Air pollution exposure during fetal life, brain morphology, and cognitive function in school-age children

Mònica Guxens, MD; Małgorzata J. Lubczyńska, MSc; Ryan L. Muetzel, PhD; Albert Dalmau-Bueno, MPH; Vincent W.V. Jaddoe, MD; Gerard Hoek, PhD; Aad van der Lugt, MD; Frank C. Verhulst, MD; Tonya White, MD; Bert Brunekreef, PhD; Henning Tiemeier, MD; Hanan El Marroun, PhD

ISGlobal, Barcelona, Spain (Guxens, Lubczyńska, Dalmau-Bueno)

Pompeu Fabra University, Barcelona, Spain (Guxens, Lubczyńska, Dalmau-Bueno)

Spanish Consortium for Research on Epidemiology and Public Health (CIBERESP), Instituto de Salud Carlos III, Spain (Guxens, Lubczyńska, Dalmau-Bueno)

Department of Child and Adolescent Psychiatry/Psychology, Erasmus University Medical Centre-Sophia Children's Hospital, Rotterdam, The Netherlands (Guxens, Muetzel, Verhulst, White, Tiemeier, El Marroun)

The Generation R Study Group, Erasmus University Medical Centre, Rotterdam, The Netherlands (Muetzel, Jaddoe, Tiemeier, El Marroun)

Department of Pediatrics, Erasmus University Medical Centre-Sophia Children's Hospital, Rotterdam, The Netherlands (Jaddoe)

Department of Epidemiology, Erasmus University Medical Centre, Rotterdam, The Netherlands (Jaddoe, Tiemeier)

Department of Radiology and Nuclear Medicine, Erasmus University Medical Centre, Rotterdam, The Netherlands (van der Lugt, White)

Institute for Risk Assessment Sciences, Utrecht University, Utrecht, The Netherlands (Goek, Brunekreef) 
Julius Center for Health Sciences and Primary Care, University Medical Center Utrecht, Utrecht, The Netherlands (Brunekreef)

Author Contributions: Drs Guxens and El Marroun had full access to all of the data in the study and take responsibility for the integrity of the data and the accuracy of the data analysis Concept and design: Guxens, El Marroun, Tiemeier Acquisition, analysis, or interpretation of data: Guxens, Muetzel, Jaddoe, Hoek, van der Lugt, Verhulst, White, Brunekreef, Tiemeier, El Marroun Drafting of the manuscript: Guxens, El Marroun Critical revision of the manuscript for important intellectual content: All authors Statistical analysis: Guxens, El Marroun, Dalmau-Bueno

Obtained funding: Jaddoe, Hoek, van der Lugt, Verhulst, White, Brunekreef, Tiemeier Administrative, technical, or material support: All authors

Supervision: Guxens, El Marroun

Correspondence to: Dr. Mònica Guxens. Barcelona Institute for Global Health (ISGlobal) Campus Mar. Carrer Dr. Aiguader 88, 08003 Barcelona, Spain. Phone: +34932147330. Email: monica.guxens@isglobal.org

Keywords: neuroimaging, particulate matter, environmental pollution, cohort studies, child development, cognition

Short title: Air pollution and brain morphology in children

Words in abstract: 249

Words in article body: 3905 Number of figures: 5 
Number of tables: 3

Number of supplemental information: 1 


\begin{abstract}
Objective. Air pollution exposure during fetal life has been related to impaired child neurodevelopment but it is unclear if brain structural alterations underlie this association. The authors assessed whether air pollution exposure during fetal life alters brain morphology and whether these alterations mediate the association between air pollution exposure during fetal life and cognitive function in school-age children.
\end{abstract}

Method. We used data from a population-based birth cohort set up in Rotterdam, The Netherlands (2002-2006). Residential levels of air pollution during the entire fetal period were calculated using land-use regression models. Structural neuroimaging and cognitive function were performed at age 6-10 years $(n=783)$. Models were adjusted for several socioeconomic and life-style characteristics.

Results. Mean fine particle levels were $20.2 \mu \mathrm{g} / \mathrm{m}^{3}$ (range 16.8-28.1). Children exposed to higher particulate matter levels during fetal life had thinner cortex in several brain regions of both hemispheres (e.g. cerebral cortex of the precuneus region in the right hemisphere was $0.045 \mathrm{~mm}$ thinner (95\% Confidence Interval 0.028-0.062) for each $5 \mu \mathrm{g} / \mathrm{m}^{3}$ increase in fine particles). The reduced cerebral cortex in precuneus and rostral middle frontal regions partially mediated the association between exposure to fine particles and impaired inhibitory control. Air pollution exposure was not associated with global brain volumes.

Conclusions. Exposure to fine particles during fetal life was related to child brain structural alterations of the cerebral cortex and these alterations partially mediated the association between exposure to fine particles during fetal life and impaired child inhibitory control. Such cognitive impairment at early ages could have significant long-term consequences. 


\section{Introduction}

Air pollution is a global risk factor for various adverse health effects in humans (1-7). There is increasing evidence indicating that air pollution exposure is also related to an impairment of the central nervous system through chronic neuroinflammation and microglia activation which can lead to neuronal damage (8). Since pregnancy and the first years of life are critical windows of developmental vulnerability for the brain, exposure to air pollution during this period could cause permanent changes in the brain even at low levels of exposure $(9,10)$.

Several epidemiological studies have assessed the association between air pollution exposure during early life and child neurodevelopment (11-16). These studies have found that air pollution exposure during pregnancy or during the first years of life was associated with lower cognitive or psychomotor function and higher behavior problems including autism spectrum disorders. However, they mainly used neuropsychological or clinical instruments to evaluate child neurodevelopment, limiting our understanding of which brain structural and functional alterations underlie these associations. Only few small studies have started using magnetic resonance imaging (MRI) techniques to assess relationships with air pollution (1720). Three studies found an association between higher exposure to air pollution at home during fetal life or early childhood and white matter abnormalities in children at seven to thirteen years old (17-19). A fourth study in children aged eight to twelve years showed a relationship between air pollution exposure at school and lower functional integration and segregation in key brain networks (20). Despite the fact that prior studies have not found an association between air pollution exposure and cortical thickness, the study of brain morphology is key in providing insights in the underlying neurobiological pathways.

Therefore, the aims of the present study were i) to assess the association between air pollution exposure during fetal life and brain morphology in school-age children and ii) to assess the mediation role of brain morphology on the association between air pollution 
exposure during fetal life and cognitive function in school-age children. Cognitive function is the result of integration of functions of many different brain regions, and thus there was no $a$ priori hypothesis on which specific brain regions would be affected by air pollution exposure during fetal life as no other similar studies have been performed so far. Thus, we used an exploratory approach to examine the association of exposure to air pollutants and brain surface measures.

\section{Methods and Materials}

\section{Population and study design}

This study was embedded in the Generation R Study, a population-based birth cohort study from fetal life onwards in Rotterdam, the Netherlands (21). A total of 8,879 pregnant women were enrolled and children were born between April 2002 and January 2006. A subgroup of children aged between six and ten years participated in an MRI sub-study (22). Briefly, a total of 1,932 were invited to participate in this sub-study. Children were oversampled based on certain maternal exposures during pregnancy (i.e. cannabis, nicotine, selective serotonin reuptake inhibitors, depressive symptoms, and plasma folate levels) and child behavior problems (i.e. attention deficit hyperactivity disorder, pervasive developmental problems, dysregulation problems, and aggressive problems). Exclusion criteria comprised contradictions for the MRI procedure, severe motor or sensory disorders, neurological disorders, head injuries with loss of consciousness, and claustrophobia. Among those invited, 155 did not answer the invitation call, 447 refused to participate, and 5 could not participate due to contraindications for the MRI procedure. Among the 1,325 that attended the MRI visit, after excluding those with poor MRI data quality and major abnormalities, MRI measurements were available for 1,070 children. Finally, after excluding those without air pollution estimations during fetal life, 783 children were included in the present study. This 
study was approved by the Medical Ethics Committee of the Erasmus Medical Centre in Rotterdam, The Netherlands. Written informed consent was obtained from parents.

\section{Air pollution exposure}

Air pollution levels at mothers' home addresses for the entire fetal period were estimated following a standardized procedure described elsewhere (23-25). Briefly, air pollution monitoring campaigns of three two-week periods of nitrogen dioxide $\left(\mathrm{NO}_{2}\right)$ in 80 sites and particulate matter $(\mathrm{PM})$ with aerodynamic diameters $<10 \mu \mathrm{m}\left(\mathrm{PM}_{10}\right)$ and $<2.5 \mu \mathrm{m}\left(\mathrm{PM}_{2.5}\right.$ or fine particles), and absorbance of fine particles (a proxy for elemental carbon) in 40 sites were performed in 2009-2010 across The Netherlands and Belgium $(26,27)$. Coarse particle concentration was calculated as the difference between $\mathrm{PM}_{10}$ and $\mathrm{PM}_{2.5}$. The three measurements were averaged, adjusting for temporal variation using data from a centrally located background monitoring site with year-round monitoring. Land-use regression models were developed using predictor variables on nearby traffic intensity, population/household density, and land use derived from Geographic Information Systems to explain spatial variation of annual average concentrations (23-25). These models were then used to assign air pollution levels at mothers' home addresses during the entire fetal period using the exact geographical $\mathrm{x}$ and $\mathrm{y}$ coordinates that corresponded to the addresses reported by each participant. Seven available routine background monitoring network sites were simultaneously used to back-extrapolate to the exact fetal period $(6,25)$ accounting for the changes of home address during pregnancy (Supplemental Methods S1). This resulted in a single, time-adjusted mean air pollution concentration for each participant for the entire fetal period. Previous research supports stability of measured and modeled spatial contrast in air pollutants for periods up to 18 years (28). 


\section{Magnetic Resonance Imaging}

Structural MRI scans were obtained on a 3-Tesla scanner (Discovery MR750, GE Healthcare, Milwaukee, USA). Using an 8-channel head coil, a whole-brain high-resolution T1-weighted inversion recovery fast spoiled gradient recalled (IR-FSPGR) sequence was obtained. The scan parameters were the following: repetition time $=10.3 \mathrm{~ms}$, echo time $=4.2 \mathrm{~ms}$, inversion time $=350 \mathrm{~ms}$, flip angle $=16^{\circ}, 186$ contiguous slices with a thickness of $0.9 \mathrm{~mm}$, and in-plane resolution $=0.9 \times 0.9 \mathrm{~mm}$.

To minimize movement children participated in a mock scanning session prior to the actual MRI scanning to introduce them to the scanning environment (22). In the scanner, care was taken that children were comfortable and soft cushions were used to assist with head immobilization. However, it was still possible that children moved in the scanner. Image quality assurance was performed in 2 steps. First, a visual inspection of the image quality of the T1 sequence was done at the scanner. If the image quality was poor or unusable, the scan was repeated with extra instructions for children to lie still. Second, a visual inspection of the surface reconstruction quality was done after the images were processed through the FreeSurfer pipeline. Both steps of quality control had to be passed successfully for data to be included in the analyses.

Cortical reconstruction and volumetric segmentation of global brain measures was performed with the Freesurfer image analysis suite version 5.1.0, (http://surfer.nmr.mgh.harvard.edu/). Briefly, cortical thickness at each vertex was measured by calculating the shortest distance from the white matter to the pial surface. Procedures for the measurement of cortical thickness have been validated against histological analysis and manual measurements (29). Volumetric measures included total brain volume, cortical gray matter volume, cortical white matter volume, subcortical gray matter volumes (i.e., caudate, 
putamen, pallidum, accumbens, hippocampus, amygdala, and thalamus), and ventricular volume. Freesurfer morphometric procedures have been demonstrated to show good testretest reliability across scanner manufacturers and across field strengths (30). All Freesurfer output was visually inspected and rated for quality.

\section{Cognitive function}

Children's cognitive function was assessed on the day of the scanning or shortly after using an array of subtasks from the Dutch version of the Developmental Neuropsychological Assessment test (NEPSY-II) (31). Detailed description of the test has been published previously (22). Briefly, the subtasks were chosen to tap into specific domains, including: attention and executive functioning, language, memory and learning, sensorimotor function, and visuospatial processing. Children were individually tested in a quiet room by trained investigators.

\section{Potential confounding variables}

Potential confounding variables were defined a priori based on direct acyclic graph (DAG) (Supplemental Figure S1) and on previous literature $(11,12,25)$. Parental characteristics during pregnancy were collected by questionnaires: parental educational levels, monthly household income, parental countries of birth, parental ages, maternal prenatal smoking, maternal prenatal alcohol use, maternal parity, family status, and maternal psychological distress (using the Brief Symptom Inventory). Parental weights and heights were measured or self-reported at the first trimester of pregnancy in the research center. Pre-pregnancy body mass index $\left(\mathrm{kg} / \mathrm{m}^{2}\right)$ was calculated. Child's sex and date of birth were obtained from hospital or national registries. Child genetics ancestry was estimated based on the genome-wide SNP data from whole blood at birth and 4 principal components of ancestry were included to better 
correct for population stratification $(32,33)$. Maternal intelligence quotient was assessed at child's age of six years with the Ravens Advanced Progressive Matrices Test, set I. Child's age at scanning was also collected.

\section{Statistical analyses}

We performed whole-brain, vertex-wise statistics using the Freesurfer QDEC module (query, design, estimate contrast) for each air pollutant adjusting for child's sex and age. As there are many vertices per hemisphere $(\sim 160,000)$, analyses were corrected for multiple testing using the built-in Monte Carlo null- Z simulations with 10,000 iterations ( $\mathrm{p}<.01)$. Due to limitations in modeling strategy with QDEC (types of variables, number of confounding variables, and inability to impute missingness in confounding variables), subject-level data from the identified regions associated with each air pollutant were imported into STATA (version 14; StataCorporation, College Station, TX, USA) for the following analysis.

Among children with available data on air pollution, neuroimaging, and cognitive function we performed multiple imputation of missing values of potential confounding variables using chained equations to generate 25 complete datasets (34). The percentage of missing values was relatively low and distributions in imputed datasets were similar to those observed (Supplemental Table S1). Children included in the analysis $(n=783)$ were more likely to have mothers from a higher socioeconomic position compared to those that were not included, among children selected for the MRI sub-study ( $\mathrm{n}=1,149)$ (Supplemental Table S2). This was also the case when we compared our study population to the not included children from the full cohort recruited in pregnancy $(n=8,097)$ (Supplemental Table S3). We used inverse probability weighting to correct for lost to follow-up, i.e. to account for potential selection bias when including only participants with available data as compared to the full cohort recruited at pregnancy (35). 
We used linear regression analyses to assess the associations between i) exposure to each air pollutant and global brain measures and ii) exposure to each air pollutant and the cortical thickness of each identified region in the QDEC analysis. Models were adjusted for all potential confounding variables described in the previous section.

Next we selected the tasks that assessed the cognitive function involved with each identified region based on the literature. We assessed whether both air pollution exposure and the cortical thinness of these regions were associated with the selected cognitive functions using adjusted negative binomial or linear regression models depending on the distribution of the outcome. We then applied causal mediation analysis providing estimation of the natural direct effect (NDE), the natural indirect effect (NIE), and the total effect (Supplemental Methods S2) (36). Briefly, we assessed the direct and indirect effects of air pollution exposure during fetal life on cognitive function. We tested whether part of the indirect effect was mediated by cortical thinness (Supplemental Figure S1). We used negative binomial regression for the outcome regression model and linear regression for the mediator regression model. Standard errors were calculated using bootstrapping. All models were adjusted for all potential confounding variables described in the previous section. The total effect results as the product of the natural direct effect (NDE) and natural indirect effect (NIE). We also calculated the proportion mediated as incidence rate ratio $(\mathrm{IRR})^{\mathrm{NDE}}\left(\mathrm{IRR}^{\mathrm{NIE}}-\right.$ $1) /\left(\operatorname{IRR}^{\mathrm{NDE}} \operatorname{IRR}^{\mathrm{NIE}}-1\right)$.

We performed sensitivity analysis of the association between air pollutants and the cortical thickness of each identified region in the whole-brain analysis: i) we restricted the analysis to those children without attention deficit hyperactivity disorder, pervasive developmental problems, dysregulation problems, and aggressive problems and ii) we restricted the analysis to those children from non-smoking mothers during pregnancy. 


\section{Results}

Participant characteristics of the study population are shown in Table 1 and Supplemental Table S4. Mean residential air pollution exposure during fetal life was $39.3 \mu \mathrm{g} / \mathrm{m}^{3}$ for $\mathrm{NO}_{2}$ (range $25.3-73.3$ ) and $20.2 \mu \mathrm{g} / \mathrm{m}^{3}$ for fine particles (range 16.8-28.1). Correlation between air pollutants was between 0.43 and 0.79 (Supplemental Table S5). Mothers exposed to higher air pollution levels during fetal life were more likely to have a higher level of education, to have a higher household income, and to be Dutch compared to those exposed to lower levels (Supplemental Table S6-9).

We did not find significant associations between air pollution exposure during fetal life and global brain volume measures (Table 2). Children exposed to higher particulate matter levels during fetal life had thinner cortices in several brain regions in both hemispheres (Figure 1). Sizes of associated brain regions varied between 532 and 2,995mm² (Supplemental Table S10). Mean thickness of these brain regions was between 2.31 and $3.17 \mathrm{~mm}^{2}$ (with a minimum thickness of 1.61 to $2.23 \mathrm{~mm}^{2}$ and a maximum thickness of 3.23 to $3.97 \mathrm{~mm}^{2}$ ). After adjusting for potential confounding variables, exposure to particulate matter levels remained strongly associated with thinner cortices of all identified regions (e.g. cerebral cortex of the precuneus region was $0.045 \mathrm{~mm}$ thinner (95\% Confidence Interval (CI) 0.028 to 0.062) for each $5 \mu \mathrm{g} / \mathrm{m}^{3}$ increase in fine particles) (Table 3). We observed similar results in the different sensitivity analysis (Supplemental Tables S11-12).

Based on the cognitive functions involved with each identified region, we selected the attention and executive functioning tasks for all regions except for the fusiform region where we selected the memory for faces tasks (Supplemental Methods S3). Fine particles exposure during fetal life was associated with a higher number of inhibition errors of the response set 
task (IRR $1.07 ; 95 \%$ CI 1.01 to 1.14 per each $5 \mu \mathrm{g} / \mathrm{m}^{3}$ increase in fine particles) (Table 4 ). No significant associations were observed for the other relationships. A thinner cortex in the precuneus region and the rostral middle frontal region was also associated with a higher number of inhibition errors of that tasks (IRR 1.32 ; $95 \%$ CI 1.00 to 1.77 per each $1 \mathrm{~mm}$ decrease of the cortex in the precuneus region and IRR $1.69 ; 95 \%$ CI 1.09 to 2.61 per each $1 \mathrm{~mm}$ decrease of the cortex in the rostral middle frontal region) (Table 5). We finally found that the reduced cortical thickness in the precuneus and rostral middle frontal regions partially mediated the observed association between fine particles exposure during fetal life and the increase number of inhibition errors (natural indirect effect: IRR 1.01; 95\% CI 1.00 to 1.02 per each $1 \mathrm{~mm}$ decrease of the cortex in the precuneus region and in the rostral middle frontal region) (Figure 2). The proportion mediated through the reduced cortical thickness in each of the regions was estimated to be $15 \%$.

\section{Discussion}

The present study suggests that particulate matter exposure during fetal life was associated with a thinner cortex in several brain regions and to an impaired inhibitory control in schoolage children. The structural alterations in the precuneus and the rostral middle frontal regions partially mediated the association between fine particles exposure and impaired inhibitory control. No association was found between air pollution exposure and global brain volume measures.

Several epidemiological studies have found that air pollution exposure during fetal life was associated with lower cognitive function (11-14). However, very few studies have investigated which brain structural and functional alterations underlie these associations. Child cognitive function is the result of integration of functions of many different brain regions, and thus we did not have a priori hypothesis on which specific brain regions could be 
affected by air pollution exposure during fetal life. In our study we identified that some specific brain regions had thinner cortex in relation to air pollution exposure during fetal life. We do not have a hypothesis why air pollution exposure during fetal life is affecting the grey matter of specific brain regions instead of having a more wide-spread effect. One explanation would be that this is due to the different development of each brain region across adolescence. For example, cortical volume of the frontal lobe showed a relatively stable trajectory in late childhood and an accelerated thinning in adolescence, while decelerating trajectories with increasing age were seen for thickness in the parietal and occipital lobes (37). Further longitudinal studies are warranted to better understand the potential associations at different ages.

To date, only one small study assessed the relationship between air pollution exposure during fetal life and structural brain morphology in 40 children at seven to nine years old from New York City, taking also an exploratory approach as we did in our study (17). Peterson et al. did not find an association between personal polycyclic aromatic hydrocarbons exposure during the third trimester of pregnancy and any measure of cortical thickness. However, they found an association between higher personal polycyclic aromatic hydrocarbons exposure during the third trimester of pregnancy and a lower white matter surface, almost exclusively to the left hemisphere of the brain (17). In contrast with this previous study, we did not find a relationship between exposure to air pollutants during fetal life and white matter volume using a much larger sample of children at a similar age. As there is indication that white matter could be one of the brain structural affected by air pollution exposure during fetal life, future research should focus on white matter microstructure which could uncover deficits that are not apparent with simple white matter volumetric measures.

During pregnancy, the detoxification mechanisms of the developing fetus are still immature and the placenta grants only a partial protection against the entry of environmental 
toxicants $(10,9)$. Hence, when the mother is exposed to air pollution, air pollutants might alter the prenatal brain development as a result of oxidative stress and systemic inflammation leading to chronic neuroinflammation, microglia activation, and neuronal migration damage (8). Early disturbances in neuronal path finding, abnormalities in cell proliferation, and differentiation eventually result in a thinner cortex during childhood. Although the prenatal period is considered particularly vulnerable period for brain development, the brain continues to develop until adolescence and postnatal air pollution exposure could also play a role on brain development $(8,11,12)$. In the New York City study, they also explored the relationship between postnatal urinary polycyclic aromatic hydrocarbon metabolites and structural brain morphology not finding an association with cortical thickness but showing a lower white matter surface in dorsal prefrontal regions bilaterally (17). Two small studies including around 30 children at six to fourteen years old found that children living in Mexico City had lower white matter volumes and higher rates of subcortical prefrontal white matter hyperintensities compared to those living in a low polluted city of Mexico (18, 19). Again, white matter seems to be influenced by air pollution exposure. Furthermore, in 263 children aged eight to twelve from Barcelona, Spain, higher elemental carbon and $\mathrm{NO}_{2}$ exposure at school was not associated with brain structure but associated with lower functional integration and segregation in key brain networks relevant to both inner mental processes and stimulusdriven mental operations (20). That study was the first to shown that air pollution exposure might also alter brain functionality which leads to a slower brain maturation. Overall, air pollution exposure to both prenatal and postnatal periods has shown to impair brain development. Further studies are needed to disentangle the specific brain alterations due to prenatal and postnatal air pollution exposure.

Interestingly, our study is the first study showing that fine particles exposure during fetal life was associated with an impaired inhibitory control in school-age children and that 
thinner cortex in the precuneus and the rostral middle frontal regions partially mediated this association. Inhibitory control, a key component of executive functions, regulates the selfcontrol of resisting temptations and acting impulsively and the selective attention (38). Impaired inhibitory control has been related to several mental health problems such as addictive behaviors (39) or attention deficit hyperactivity disorder (40). The previous study carried out in New York City found that the white matter disruption partially mediated the association between prenatal polycyclic aromatic hydrocarbons exposure and a slower information processing speed in children (17). Therefore, we hypothesize that air pollution exposure during fetal life could lead to brain structural changes and these to specific cognitive delays.

In our study, mean residential $\mathrm{NO}_{2}$ levels during fetal life were just at the EU limit of $40 \mu \mathrm{g} / \mathrm{m}^{3}$, with $45 \%$ of our population having higher levels. Regarding fine particles, mean residential levels were clearly below the EU limit of $25 \mu \mathrm{g} / \mathrm{m}^{3}$, with only $0.5 \%$ of our population above that limit (41). However, as we observed in our study brain development effects in relationship to fine particles levels below the current EU limit, as well as other studies have found relationships with several health endpoints including natural-cause mortality, cardiovascular and respiratory diseases, cognitive decline, and fetal growth development (1-7), we cannot warrant that this limit is safe. The World Health Organization set a lower limit of $10 \mu \mathrm{g} / \mathrm{m}^{3}$ for fine particles (42), and in our study we have all our population above this limit. Further health effect research needs to bring more insight into the safety of the current levels of air pollution in our cities.

The strengths of our study are the large number of study participants with imaging data, the prospective and longitudinal nature of the study, the detailed information of air pollution estimations at the individual level during the entire fetal period, and the availability of adjusting the imaging analysis for a large number of socioeconomic and lifestyle factors 
known to be associated with both air pollution exposure and brain development. Nevertheless, we cannot discard that our results might still be affected by residual confounding due to the unavailability of other relevant potential confounding variables. Another limitation of our study was that children with exposure and outcome data were more likely to have mothers from higher socioeconomic position than those without these data but recruited at the beginning of the cohort in early pregnancy, which could lead to selection bias in our results. To reduce this possible selection bias, we used advanced statistical methods including multiple imputation combined with inverse probability weighting. However, we could have missed variables related to this potential selection bias that that would have a stronger effect in the results. In addition, there is the possibility of chance findings in the observed associations in the current study. The imaging analysis was corrected for multiple testing of the whole-brain, vertex-wise statistics as we have many vertices per hemisphere. However, the causal mediation analysis was hypothesis-driven and we decided not to correct for multiple testing as this could increase type 2 error $(43,44)$. Instead, our conclusions were based on the general patterns of associations observed in the study. This has been the first study showing that brain structural alterations seem to partially mediate the association between air pollution exposure during fetal life and an impaired cognitive function. Further studies are warranted to replicate these findings and better understand this association.

\section{Conclusions}

We showed that fine particles exposure during fetal life was both related to child brain structural alterations of the cerebral cortex and to an impairment of an essential executive function such as inhibitory control. Moreover, the identified structural alterations in two specific regions partially mediated the association between fine particles exposure during fetal life and the impaired inhibitory control. Such cognitive impairment at early ages could have 
significant long-term consequences including increased risk of mental disorders, low academic achievement, and diminished economic productivity (38), in particular due to the ubiquity of the exposure. 


\section{Conflict of interest Disclosures: None reported}

Previous presentation: 28th Annual International Society for Environmental Epidemiology Conference,, September 1-4, 2016, Rome, Italy; XXXIV Scientific Meeting of the Spanish Society of Epidemiology, September 14-16, 2016, Sevilla, Spain; 10th World Congress Developmental Origins of Health and Disease, October 15-17, 2017, Rotterdam, The Netherlands

Funding/Suport: The Generation R Study is conducted by the Erasmus Medical Center in close collaboration with the School of Law and Faculty of Social Sciences of the Erasmus University Rotterdam, the Municipal Health Service Rotterdam area, Rotterdam, the Rotterdam Homecare Foundation, Rotterdam and the Stichting Trombosedienst \& Artsenlaboratorium Rijnmond (STAR-MDC), Rotterdam. We gratefully acknowledge the contribution of children and parents, general practitioners, hospitals, midwives and pharmacies in Rotterdam. The general design of Generation R Study is made possible by financial support from the Erasmus Medical Center, Rotterdam, the Erasmus University Rotterdam, the Netherlands Organization for Health Research and Development (ZonMw), the Netherlands Organization for Scientific Research (NWO), and the Ministry of Health, Welfare and Sport. Air pollution exposure assessment was possible by funding from the European Community's Seventh Framework Program (GA\#211250, GA\#243406). In addition, the study was made possible by financial support from the Netherlands Organization for Health Research and Development (ZonMW Geestkracht Program 10.000.1003 \& ZonMw TOP 40-00812-98-11021). The neuroimaging infrastructure was funded via TOP project number 91211021 and supercomputing computations for imaging processing were supported by the NWO Physical Sciences Division (Exacte Wetenschappen) and SURFsara 
(Lisa compute cluster, www.surfsara.nl). Research described in this article was also conducted under contract to the Health Effects Institute (HEI), an organization jointly funded by the United States Environmental Protection Agency (EPA) (Assistance Award No. R82811201) and certain motor vehicle and engine manufacturers. The contents of this article do not necessarily reflect the views of HEI, or its sponsors, nor do they necessarily reflect the views and policies of the EPA or motor vehicle and engine manufacturers. Vincent W.V. Jaddoe and Henning Tiemeier received funding from the Netherlands Organization for Health Research and Development (VIDI 016.136.361 and NWO-grant 016.VICI.170.200, respectively), the European Research Council (ERC-2014-CoG-64916), and the European Union's Horizon 2020 research and innovation programme under grant agreement No. 633595 (DynaHEALTH) and No. 733206 (LifeCycle). The Erasmus University Rotterdam granted Dr. El Marroun a personal fellowship (EUR Fellow 2014) and supported this work financially. Mònica Guxens is funded by a Miguel Servet fellowship (MS13/00054 and CP13/00054) awarded by the Spanish Institute of Health Carlos III (Ministry of Economy and Competitiveness).

Role of the Funder/Sponsors: The funding organizations for this study had no involvement in the design and conduct of the study; collection, management, analysis, and interpretation of the data; preparation, review, or approval of the manuscript; or the decision to submit the manuscript for publication. 


\section{References}

1. Jerrett M (2015): Atmospheric science: The death toll from air-pollution sources. Nature. 525: 330-331.

2. Beelen R, Raaschou-Nielsen O, Stafoggia M, Andersen ZJ, Weinmayr G, Hoffmann B, et al. (2014): Effects of long-term exposure to air pollution on natural-cause mortality: an analysis of 22 European cohorts within the multicentre ESCAPE project. Lancet Lond Engl. 383: 785-795.

3. Kaufman JD, Adar SD, Barr RG, Budoff M, Burke GL, Curl CL, et al. (2016): Association between air pollution and coronary artery calcification within six metropolitan areas in the USA (the Multi-Ethnic Study of Atherosclerosis and Air Pollution): a longitudinal cohort study. Lancet Lond Engl. 388: 696-704.

4. Gauderman WJ, Urman R, Avol E, Berhane K, McConnell R, Rappaport E, et al. (2015): Association of Improved Air Quality with Lung Development in Children. $N$ Engl $J$ Med. 372: 905-913.

5. Raaschou-Nielsen O, Andersen ZJ, Beelen R, Samoli E, Stafoggia M, Weinmayr G, et al. (2013): Air pollution and lung cancer incidence in 17 European cohorts: prospective analyses from the European Study of Cohorts for Air Pollution Effects (ESCAPE). Lancet Oncol. 14: 813-822.

6. Pedersen M, Giorgis-Allemand L, Bernard C, Aguilera I, Andersen A-MN, Ballester F, et al. (2013): Ambient air pollution and low birthweight: a European cohort study (ESCAPE). Lancet Respir Med. 1: 695-704.

7. Chen H, Kwong JC, Copes R, Tu K, Villeneuve PJ, van Donkelaar A, et al. (2017): Living near major roads and the incidence of dementia, Parkinson's disease, and multiple sclerosis: a population-based cohort study. Lancet Lond Engl. . doi: 10.1016/S01406736(16)32399-6. 
8. Block ML, Elder A, Auten RL, Bilbo SD, Chen H, Chen J-C, et al. (2012): The outdoor air pollution and brain health workshop. NeuroToxicology. 33: 972-984.

9. Grandjean P, Landrigan PJ (2014): Neurobehavioural effects of developmental toxicity. Lancet Neurol. 13: 330-338.

10. Rice D, Barone S (2000): Critical periods of vulnerability for the developing nervous system: evidence from humans and animal models. Environ Health Perspect. 108: $511-533$.

11. Guxens M, Sunyer J (2012): A review of epidemiological studies on neuropsychological effects of air pollution. Swiss Med Wkly. 141: w13322.

12. Suades-González E, Gascon M, Guxens M, Sunyer J (2015): Air Pollution and Neuropsychological Development: A Review of the Latest Evidence. Endocrinology. 156: $3473-3482$.

13. Chiu Y-HM, Hsu H-HL, Coull BA, Bellinger DC, Kloog I, Schwartz J, et al. (2016): Prenatal particulate air pollution and neurodevelopment in urban children: Examining sensitive windows and sex-specific associations. Environ Int. 87: 56-65.

14. Sentís A, Sunyer J, Dalmau-Bueno A, Andiarena A, Ballester F, Cirach M, et al. (2017): Prenatal and postnatal exposure to NO2 and child attentional function at 4-5years of age. Environ Int. 106: 170-177.

15. Sunyer J, Esnaola M, Alvarez-Pedrerol M, Forns J, Rivas I, López-Vicente M, et al. (2015): Association between Traffic-Related Air Pollution in Schools and Cognitive Development in Primary School Children: A Prospective Cohort Study. PLoS Med. 12: e1001792.

16. Lubczyńska MJ, Sunyer J, Tiemeier H, Porta D, Kasper-Sonnenberg M, Jaddoe VWV, et al. (2017): Exposure to elemental composition of outdoor PM2.5 at birth and 
cognitive and psychomotor function in childhood in four European birth cohorts. Environ Int. . doi: 10.1016/j.envint.2017.09.015.

17. Peterson BS, Rauh VA, Bansal R, Hao X, Toth Z, Nati G, et al. (2015): Effects of prenatal exposure to air pollutants (polycyclic aromatic hydrocarbons) on the development of brain white matter, cognition, and behavior in later childhood. JAMA Psychiatry. 72: 531-540.

18. Calderón-Garcidueñas L, Mora-Tiscareño A, Ontiveros E, Gómez-Garza G, BarragánMejía G, Broadway J, et al. (2008): Air pollution, cognitive deficits and brain abnormalities: A pilot study with children and dogs. Brain Cogn. 68: 117-127.

19. Calderón-Garcidueñas L, Engle R, Mora-Tiscareño A, Styner M, Gómez-Garza G, Zhu H, et al. (2011): Exposure to severe urban air pollution influences cognitive outcomes, brain volume and systemic inflammation in clinically healthy children. Brain Cogn. 77: $345-355$.

20. Pujol J, Martínez-Vilavella G, Macià D, Fenoll R, Alvarez-Pedrerol M, Rivas I, et al. (2016): Traffic pollution exposure is associated with altered brain connectivity in school children. NeuroImage. 129: 175-184.

21. Jaddoe VWV, van Duijn CM, Franco OH, van der Heijden AJ, van Iizendoorn MH, de Jongste JC, et al. (2012): The Generation R Study: design and cohort update 2012. Eur J Epidemiol. 27: 739-756.

22. White T, Marroun HE, Nijs I, Schmidt M, Lugt A van der, Wielopolki PA, et al. (2013): Pediatric population-based neuroimaging and the Generation R Study: the intersection of developmental neuroscience and epidemiology. Eur J Epidemiol. 28: 99-111.

23. Beelen R, Hoek G, Vienneau D, Eeftens M, Dimakopoulou K, Pedeli X, et al. (2013): Development of NO2 and NOx land use regression models for estimating air pollution 
exposure in 36 study areas in Europe - The ESCAPE project. Atmos Environ. 72: 1023.

24. Eeftens M, Beelen R, de Hoogh K, Bellander T, Cesaroni G, Cirach M, et al. (2012): Development of Land Use Regression Models for PM2.5, PM2.5 Absorbance, PM10 and PMcoarse in 20 European Study Areas; Results of the ESCAPE Project. Environ Sci Technol. 46: 11195-11205.

25. Guxens M, Garcia-Esteban R, Giorgis-Allemand L, Forns J, Badaloni C, Ballester F, et al. (2014): Air pollution during pregnancy and childhood cognitive and psychomotor development: six European birth cohorts. Epidemiol Camb Mass. 25: 636-647.

26. Cyrys J, Eeftens M, Heinrich J, Ampe C, Armengaud A, Beelen R, et al. (2012): Variation of NO2 and NOx concentrations between and within 36 European study areas: Results from the ESCAPE study. Atmos Environ. 62: 374-390.

27. Eeftens M, Tsai M-Y, Ampe C, Anwander B, Beelen R, Bellander T, et al. (2012): Spatial variation of PM2.5, PM10, PM2.5 absorbance and PMcoarse concentrations between and within 20 European study areas and the relationship with NO2 - Results of the ESCAPE project. Atmos Environ. 62: 303-317.

28. Gulliver J, de Hoogh K, Hansell A, Vienneau D (2013): Development and backextrapolation of $\mathrm{NO} 2$ land use regression models for historic exposure assessment in Great Britain. Environ Sci Technol. 47: 7804-7811.

29. Kuperberg GR, Broome MR, McGuire PK, David AS, Eddy M, Ozawa F, et al. (2003): Regionally localized thinning of the cerebral cortex in schizophrenia. Arch Gen Psychiatry. 60: 878-88.

30. Reuter M, Schmansky NJ, Rosas HD, Fischl B (2012): Within-subject template estimation for unbiased longitudinal image analysis. Neuroimage. 61: 1402-18. 
31. Brooks BL, Sherman EMS, Strauss E (2009): NEPSY-II: A Developmental Neuropsychological Assessment, Second Edition. Child Neuropsychol. 16: 80-101.

32. Neumann A, Noppe G, Liu F, Kayser M, Verhulst FC, Jaddoe VWV, et al. (2017): Predicting hair cortisol levels with hair pigmentation genes: a possible hair pigmentation bias. Sci Rep. 7: 8529.

33. Price AL, Patterson NJ, Plenge RM, Weinblatt ME, Shadick NA, Reich D (2006): Principal components analysis corrects for stratification in genome-wide association studies. Nat Genet. 38: 904-909.

34. Spratt M, Carpenter J, Sterne JAC, Carlin JB, Heron J, Henderson J, Tilling K (2010): Strategies for multiple imputation in longitudinal studies. Am J Epidemiol. 172: 478487.

35. Weuve J, Tchetgen Tchetgen EJ, Glymour MM, Beck TL, Aggarwal NT, Wilson RS, et al. (2012): Accounting for bias due to selective attrition: the example of smoking and cognitive decline. Epidemiol Camb Mass. 23: 119-128.

36. Valeri L, Vanderweele TJ (2013): Mediation analysis allowing for exposure-mediator interactions and causal interpretation: theoretical assumptions and implementation with SAS and SPSS macros. Psychol Methods. 18: 137-150.

37. Tamnes CK, Herting MM, Goddings A-L, Meuwese R, Blakemore S-J, Dahl RE, et al. (2017): Development of the Cerebral Cortex across Adolescence: A Multisample Study of Inter-Related Longitudinal Changes in Cortical Volume, Surface Area, and Thickness. J Neurosci. 37: 3402-3412.

38. Diamond A, Ling DS (2016): Conclusions about interventions, programs, and approaches for improving executive functions that appear justified and those that, despite much hype, do not. Dev Cogn Neurosci. 18: 34-48. 
39. Jentsch JD, Pennington ZT (2014): Reward, interrupted: Inhibitory control and its relevance to addictions. Neuropharmacology. 76 Pt B: 479-486.

40. Ma I, van Duijvenvoorde A, Scheres A (2016): The interaction between reinforcement and inhibitory control in ADHD: A review and research guidelines. Clin Psychol Rev. 44: 94-111.

41. European Commission (2017): Air Quality Standards. Brussels, Belgium. Retrieved from Available: http://ec.europa.eu/environment/air/quality/standards.htm [accessed 12 Dec 2017].

42. World Health Organization (2016): Ambient (outdoor) air quality and health. Geneva, Switzerland. $\quad$ Retrieved from Available: http://www.who.int/mediacentre/factsheets/fs313/en/ [accessed 12 Dec 2017].

43. Rothman KJ (1990): No adjustments are needed for multiple comparisons. Epidemiol Camb Mass. 1: 43-46.

44. Perneger TV (1998): What's wrong with Bonferroni adjustments. BMJ. 316: 1236-1238. 


\section{Figures legend.}

Figure 1. Differences in cortical thickness at 6-10 years of age associated with air pollution exposure during fetal life

The colored regions on the surface map represent brain regions that are thinner in relation to higher exposure to air pollution during fetal life in the right and left hemisphere (darker color indicates stronger association). Analyses were adjusted for child's sex and age. All brain regions survived the correction (Monte Carlo null-Z simulation with 10,000 iterations) for multiple comparisons $(\mathrm{p}<.01)$. 


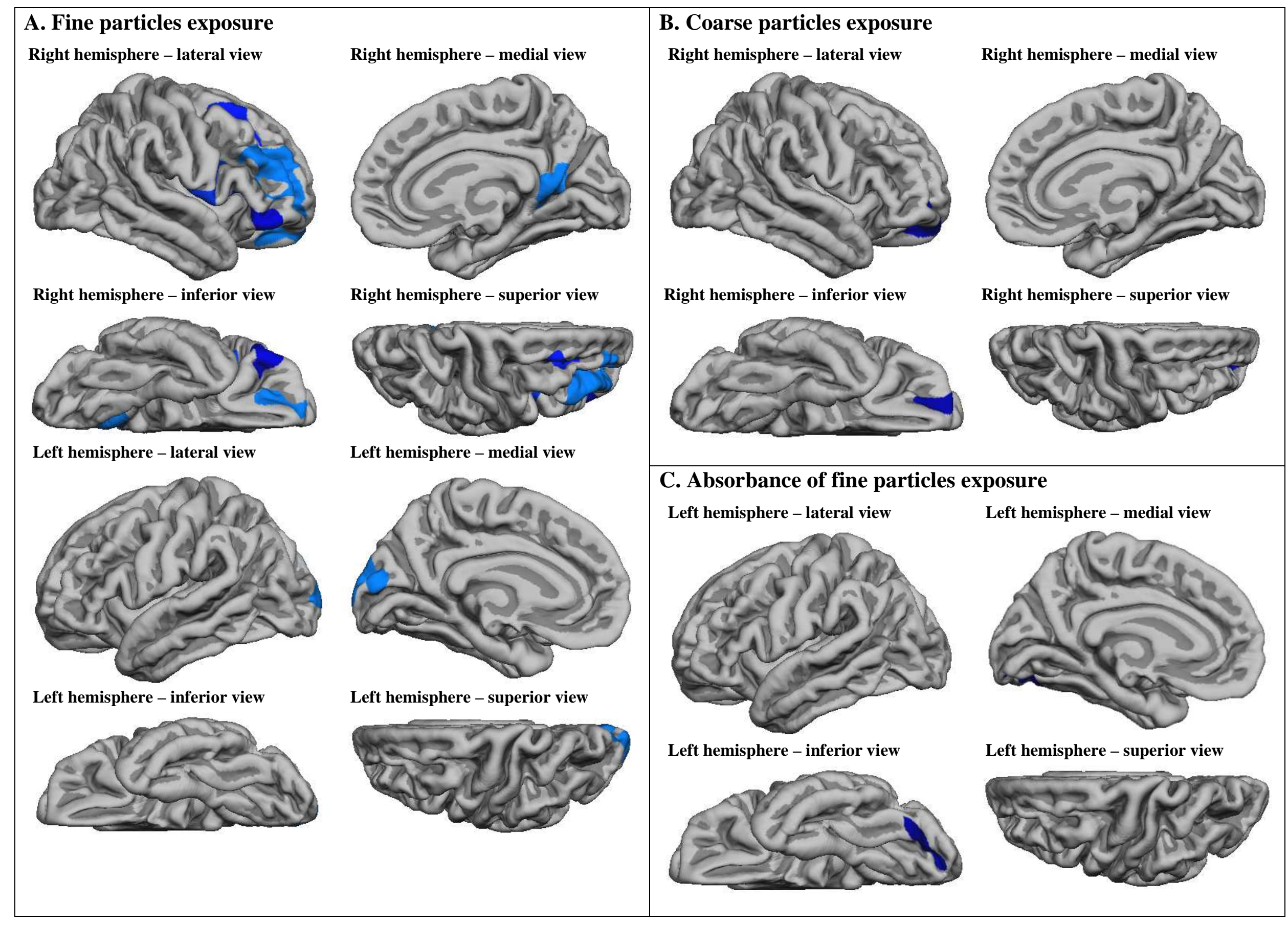


Figure 2. Causal mediation analyses between air pollution exposure during fetal life, cortical thickness (in $\mathrm{mm}$ ) in precuneus and rostral middle frontal regions, and the number of inhibition errors of the response set task at 6-10 years of age Abbreviations: CI, confidence interval; IRR, incidence risk ratio.

Incidence risk ratio (95\% Confidence Interval) from negative binomial regression models adjusted for parental educational levels, monthly household income, parental countries of birth, parental ages, maternal prenatal smoking, maternal prenatal alcohol consumption, parental body mass indexes and heights, maternal parity, family status, maternal psychological distress, maternal intelligence quotient, and child sex, age, and genetic ancestry. As results for both causal mediation analyses were identical rounded to 2 decimal places, only one table is presented. 

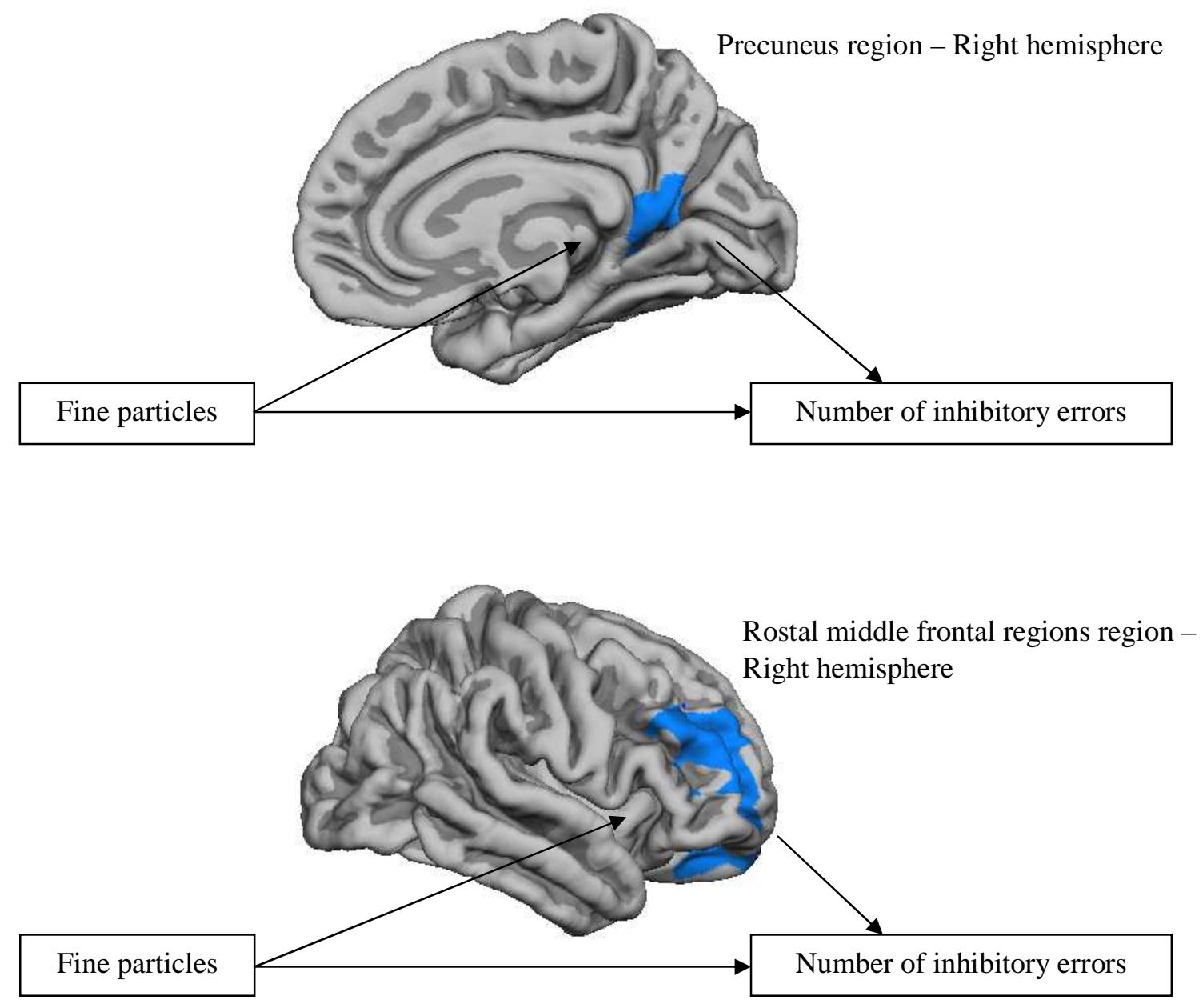

\begin{tabular}{rll}
\hline & IRR & (95\% CI) \\
\hline Natural direct effect & 1.06 & $(1.00$ to 1.12$)$ \\
Natural indirect effect & 1.01 & $(1.00$ to 1.02$)$ \\
Total effect & 1.07 & $(1.00$ to 1.13$)$ \\
\hline
\end{tabular}


Table 1. Participant characteristics and air pollution levels during fetal life

Distribution

\section{Participant characteristics}

Maternal education level

Primary education

Secondary education

44.8

University education

48.2

Paternal education level

Primary education

Secondary education

University education

Monthly household income

$<1,200 €$

$1,200 €-2,000 €$

$>2,000 €$

68.1

Maternal country of birth

The Netherlands

Cape Verde

Morocco

4.7

Surinam

Turkey

Other country of birth

Paternal country of birth

The Netherlands

Cape Verde

Morocco

Surinam

5.0

Turkey

3.4

Other country of birth

14.4

Maternal age (years)

$30.7(4.9)$

Paternal age (years)

Family status (mono $v s$. biparental)

Maternal parity (multi vs. nulliparous) 
Distribution

\begin{tabular}{|c|c|c|}
\hline Participant characteristics & Percentage & Mean (SD) \\
\hline \multicolumn{3}{|l|}{ Maternal smoking use during pregnancy } \\
\hline Never & 75.8 & \\
\hline Smoking use until pregnancy known & 6.5 & \\
\hline Continued smoking use during pregnancy & 18.2 & \\
\hline \multicolumn{3}{|l|}{ Maternal alcohol use during pregnancy } \\
\hline Never & 37.6 & \\
\hline Alcohol use until pregnancy know & 14.3 & \\
\hline Continued alcohol use during pregnancy & 48.1 & \\
\hline Maternal pre-pregnancy body mass index $\left(\mathrm{kg} / \mathrm{m}^{2}\right)$ & & $24.6(4.3)$ \\
\hline Paternal pre-pregnancy body mass index $\left(\mathrm{kg} / \mathrm{m}^{2}\right)$ & & $25.3(3.3)$ \\
\hline Maternal height $(\mathrm{cm})$ & & $168.6(7.4)$ \\
\hline Paternal height $(\mathrm{cm})$ & & $182.9(7.3)$ \\
\hline Maternal overall psychological distress & & $0.3(0.4)$ \\
\hline Maternal intelligence quotient score & & $98.4(13.9)$ \\
\hline Air pollution levels during fetal life & \multicolumn{2}{|c|}{ Median (Min-Max) } \\
\hline $\mathrm{NO}_{2}\left(\mu \mathrm{g} / \mathrm{m}^{3}\right)$ & \multicolumn{2}{|c|}{$39.3(25.3-73.3)$} \\
\hline Fine particles $\left(\mu \mathrm{g} / \mathrm{m}^{3}\right)$ & \multicolumn{2}{|c|}{$20.2(16.8-28.1)$} \\
\hline Coarse particles $\left(\mu \mathrm{g} / \mathrm{m}^{3}\right)$ & \multicolumn{2}{|c|}{$11.8(9.2-17.8)$} \\
\hline Absorbance of fine particles $\left(10^{-5} \mathrm{~m}^{-1}\right)$ & \multicolumn{2}{|c|}{$1.9(1.2-3.6)$} \\
\hline
\end{tabular}

Abbreviations: Max, maximum; Min, minimum; $\mathrm{NO}_{2}$, nitrogen dioxide, $\mathrm{SD}$, standard deviation. 
Table 2. Fully-adjusted association between air pollution exposure during fetal life and global brain volume measures at 6-10 years of age

Coef. $(95 \% \mathrm{CI})^{\mathrm{a}} \quad$ P value

$\mathrm{NO}_{2}$

Total brain volume

$124(-1118$ to 1375$) \quad .84$

Cortical gray matter volume

$-60(-853$ to 733$) \quad .88$

Cortical white matter volume

199 (-287 to 685$) \quad .42$

Subcortical gray matter volume

Ventricular volume

$36(-17$ to 89$) \quad .18$

$4(-57$ to 64$) \quad .90$

\section{Fine particles}

Total brain volume

-3079 (-7790 to 1632$) \quad .20$

Cortical gray matter volume

-2598 (-5583 to 387$) \quad .09$

Cortical white matter volume

Subcortical gray matter volume

-268 (-2096 to 1559$) \quad .77$

-60 (-258 to 138$) \quad .55$

Ventricular volume

$-96(-323$ to 131$) \quad .40$

\section{Coarse particles}

Total brain volume

Cortical gray matter volume

Cortical white matter volume

Subcortical gray matter volume

Ventricular volume

$\begin{array}{rll}-4868 & (-10337 \text { to } 822) & .09 \\ -3542 & (-7059 \text { to } 8) & .05 \\ -1129(-3215 \text { to } 1127) & .34 \\ -92(-325 \text { to } 148) & .46 \\ -100(-372 \text { to } 168) & .45 \\ & & \\ -2861 & (-18745 \text { to } 24467) & .79 \\ -2683 & (-16377 \text { to } 11012) & .70 \\ 5807 & (-2566 \text { to } 14180) & .17 \\ 418 & (-497 \text { to } 1334) & .36 \\ -64 & (-1108 \text { to } 979) & .90\end{array}$

\section{Absorbance of fine particles}

Total brain volume

Cortical gray matter volume

Cortical white matter volume

Subcortical gray matter volume

-64 (-1108 to 979$)$

84
8
2
8
90

Ventricular volume

Abbreviations: CI, confidence interval; Coef, beta coefficient; $\mathrm{NO}_{2}$, nitrogen dioxide. ${ }^{a}$ Beta coefficient (95\% Confidence Interval) from linear regression model adjusted for parental educational levels, monthly household income, parental countries of birth, parental ages, maternal prenatal smoking, maternal prenatal alcohol use, parental body mass indexes and heights, maternal parity, marital status, maternal psychological distress, maternal intelligence quotient, and child sex, age, and genetic ancestry. Coefficients represent the differences in volumes $\left(\mathrm{cm}^{3}\right)$ per each increase of $10 \mu \mathrm{g} / \mathrm{m}^{3}$ of $\mathrm{NO}_{2}, 5 \mu \mathrm{g} / \mathrm{m}^{3}$ of fine particles, $5 \mu \mathrm{g} / \mathrm{m}^{3}$ of coarse particles, and $10^{-5} \mathrm{~m}^{-1}$ of absorbance of fine particles. 
Table 3. Fully-adjusted association between air pollution exposure during fetal life and cortical thickness (in $\mathrm{mm}$ ) at 6-10 years of age

\begin{tabular}{|c|c|c|c|c|}
\hline & Hemisphere & $\begin{array}{c}\text { Size brain } \\
\text { region } \\
\left(\mathrm{mm}^{2}\right)\end{array}$ & Coef. $(95 \% \mathrm{CI})^{\mathrm{a}}$ & $P$ value \\
\hline \multicolumn{5}{|l|}{ Fine particles exposure } \\
\hline Precuneus region & Right & 936 & $-0.045(-0.062$ to -0.028$)$ & $<.001$ \\
\hline Pars opercularis region & Right & 753 & $-0.024(-0.033$ to -0.014$)$ & $<.001$ \\
\hline Pars orbitalis region & Right & 651 & $-0.028(-0.043$ to -0.012$)$ & .001 \\
\hline Rostral middle frontal region & Right & 2,995 & $-0.029(-0.041$ to -0.018$)$ & $<.001$ \\
\hline Superior frontal region & Right & 722 & $-0.029(-0.043$ to -0.016$)$ & $<.001$ \\
\hline Cuneus region & Left & 843 & $-0.022(-0.035$ to -0.009$)$ & .002 \\
\hline \multicolumn{5}{|l|}{ Coarse particles exposure } \\
\hline Lateral orbitofrontal region & Right & 565 & $-0.037 \quad(-0.059$ to -0.016$)$ & .001 \\
\hline \multicolumn{5}{|c|}{ Absorbance of fine particles exposure } \\
\hline Fusiform region & Left & 532 & $-0.105(-0.160$ to -0.049$)$ & $<.001$ \\
\hline \multicolumn{5}{|c|}{ Abbreviations: CI, confidence interval; Coef, beta coefficient. } \\
\hline \multicolumn{5}{|c|}{$\begin{array}{l}\text { a Beta coefficient (95\% Confidence Interval) from linear regression model adjusted for parental educational } \\
\text { levels, monthly household income, parental countries of birth, parental ages, maternal prenatal smoking, } \\
\text { maternal prenatal alcohol use, parental body mass indexes and heights, maternal parity, family status, maternal } \\
\text { psychological distress, maternal intelligence quotient, and child sex, age, and genetic ancestry. Coefficients } \\
\text { represent the differences in thickness (mm) per each increase of } 5 \mu \mathrm{g} / \mathrm{m}^{3} \text { of fine particles, } 5 \mu \mathrm{g} / \mathrm{m}^{3} \text { of coarse } \\
\text { particles, and } 10^{-5} \mathrm{~m}^{-1} \text { of absorbance of fine particles. }\end{array}$} \\
\hline
\end{tabular}

Guxens et al. 
Table 4. Adjusted association between air pollution levels during fetal life and cognitive function at 6-10 years of age

\begin{tabular}{lccc}
\hline & IRR & $(\mathbf{9 5 \%} \mathbf{C I})^{\mathbf{a}}$ & P value \\
\hline $\begin{array}{l}\text { Fine particles exposure } \\
\text { Auditory attention task } \\
\quad \text { Correct responses }\end{array}$ & & & \\
Commission errors & 1.00 & $(0.99$ to 1.01$)$ & .61 \\
Omission errors & 1.00 & $(0.89$ to 1.16$)$ & .95 \\
Inhibition errors & 0.98 & $(0.92$ to 1.03$)$ & .38 \\
Response set task & 1.10 & $(0.63$ to 1.93$)$ & .73 \\
Correct responses & & & \\
Commission errors & 1.01 & $(1.00$ to 1.02$)$ & .17 \\
Omission errors & 1.00 & $(0.96$ to 1.04$)$ & .79 \\
Inhibition errors & 0.97 & $(0.94$ to 1.00$)$ & .07 \\
\hline
\end{tabular}

Coarse particles exposure

Auditory attention task

\begin{tabular}{lccc} 
Correct responses & 1.00 & $(0.99$ to 1.01$)$ & .71 \\
Commission errors & 0.99 & $(0.87$ to 1.13$)$ & .88 \\
Omission errors & 0.98 & $(0.92$ to 1.05$)$ & .63 \\
Inhibition errors & 0.98 & $(0.55$ to 1.76$)$ & .95 \\
Response set task & & & \\
Correct responses & 1.01 & $(0.99$ to 1.02$)$ & .39 \\
Commission errors & 0.97 & $(0.92$ to 1.02$)$ & .19 \\
Omission errors & 0.98 & $(0.94$ to 1.02$)$ & .28 \\
Inhibition errors & 1.04 & $(0.97$ to 1.12$)$ & .24 \\
\hline
\end{tabular}

\begin{tabular}{lllll}
\hline Absorbance of fine particles exposure & & & \\
Memory for faces task & 0.22 & $(-0.24$ to 0.69$)$ & .34 \\
Memory for faces delayed task & 0.29 & $(-0.23$ to 0.81$)$ & .27 \\
\hline
\end{tabular}

Abbreviations: CI, confidence interval; Coef, beta coefficient; IRR, incidence rate ratio.

${ }^{\mathrm{a}}$ Incidence rate ratio values (95\% Confidence Interval) from negative binomial regression model or beta coefficients (95\% Confidence Interval) from linear regression model adjusted for parental educational levels, monthly household income, parental countries of birth, parental ages, maternal prenatal smoking, maternal prenatal alcohol use, parental body mass indexes and heights, maternal parity, family status, maternal psychological distress, maternal intelligence quotient, and child sex, age, and genetic ancestry.

Guxens et al. 
Table 5. Adjusted association between thinner cortical thickness (in $\mathrm{mm}$ ) and the total number of inhibitory numbers of the response set task at 6-10 years of age

\begin{tabular}{lclc}
\hline & IRR & $\mathbf{( 9 5 \% ~ C I ) ~}^{\mathbf{a}}$ & P value \\
\hline Precuneus region & 1.32 & $(1.00$ to 1.77$)$ & 0.05 \\
Pars opercularis region & 0.83 & $(0.49$ to 1.42$)$ & 0.49 \\
Pars orbitalis region & 1.16 & $(0.83$ to 1.61$)$ & 0.38 \\
Rostral middle frontal region & 1.69 & $(1.09$ to 2.61$)$ & 0.02 \\
Superior frontal region & 1.28 & $(0.89$ to 1.86$)$ & 0.18 \\
\hline
\end{tabular}

Abbreviations: $\mathrm{CI}$, confidence interval; IRR, incidence rate ratio.

${ }^{a}$ Incidence rate ratio values (95\% Confidence Interval) from negative binomial regression model adjusted for parental educational levels, monthly household income, parental countries of birth, parental ages, maternal prenatal smoking, maternal prenatal alcohol use, parental body mass indexes and heights, maternal parity, family status, maternal psychological distress, maternal intelligence quotient, and child sex, age, and genetic ancestry. CI denotes confidence interval, IRR denotes incidence risk ratio. 


\title{
Air Pollution Exposure During Fetal Life, Brain Morphology, and Cognitive Function in School-Age Children
}

\author{
Supplemental Information
}

\section{Table of contents}

Methods S1. Description of the back-extrapolation methodology of the air pollution levels ..............................2

Methods S2. Description of the causal mediation analysis .................................................................... 3

Methods S3. Cognitive function tests selected based on the identified regions ...............................................4

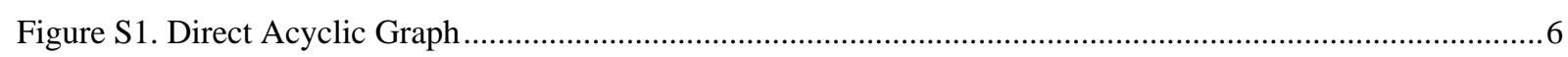

Table S1. Distribution of participant characteristics in observed and imputed datasets....................................... 7

Table S2. Comparison of participant characteristics between included and not included subjects in the study

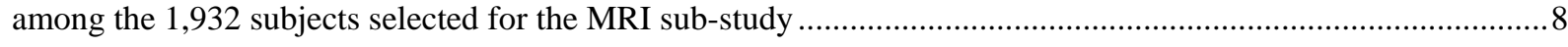

Table S3. Comparison of participant characteristics between included and not included subjects in the study among the 8,879 subjects recruited in the full cohort in pregnancy..... (1) (6) .

Table S4. Global brain volume measures (in $\mathrm{mm}$ ) in children at 6-10 years of age $. \ldots . \ldots 10$

Table S5. Spearman correlations between air pollution levels during fetal life ...........................................11

Table S6. Participant characteristics according to $\mathrm{NO}_{2}$ levels during fetal life................................................ 12

Table S7. Participant characteristics according to fine particles levels during fetal life .................................... 13

Table S8. Participant characteristics according to coarse particles levels during fetal life ..................................14

Table S9.Participant characteristics according to absorbance of fine particles levels during fetal life .................15

Table S10. Thickness (in $\mathrm{mm}$ ) of the identified thinner brain regions in relation to higher exposure to air pollution during fetal life.

Table S11. Adjusted association between air pollution exposure during fetal life and cortical thickness (in $\mathrm{mm}$ ) at 6-10 years of age restricting to those children without attention deficit hyperactivity, pervasive developmental, dysregulation, and aggressive problems....

Table S12. Adjusted association between air pollution exposure during fetal life and cortical thickness (in mm) at 6-10 years of age restricting to those children from non-smoking mothers during pregnancy .......................... 18

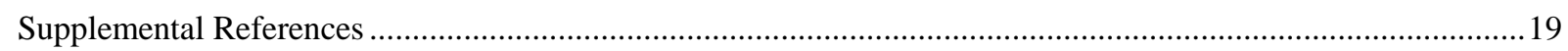




\section{Methods S1. Description of the back-extrapolation methodology of the air pollution levels}

We used a back-extrapolation procedure to estimate the levels back in time during each fetal period of each woman in order to assess if fetal period is a relevant exposure period $(1,2)$. The estimated yearly concentrations (Cyearly,i) at each home address i were combined with timespecific measurements from seven available routine background monitoring network sites by averaging the daily concentrations during 1) the year corresponding to the LUR yearly concentration (Cyearly) and 2) each fetal period $\mathrm{p}_{\mathrm{i}}$ considered $\left(\mathrm{C}_{\mathrm{i}}\right)$. The ratio $\mathrm{Cp}_{\mathrm{i}} /$ Cyearly constituted the temporal component of the model. For each pollutant, the concentration $\left(\mathrm{C}_{\mathrm{p}}, \mathrm{i}\right)$ estimated at the home address $\mathrm{i}$ during the fetal period for woman $\mathrm{i}$ was estimated as the product of the temporal $\left(\mathrm{C}_{\mathrm{p}} / \mathrm{Cyearly}\right)$ and spatial $(\mathrm{Cyearly}, \mathrm{i})$ components. In cases when air quality monitoring data from background station was unavailable for a given pollutant, we used measurements for another pollutant during the same time period as a replacement; the choice of that pollutant used to back-extrapolate another pollutant was based on an extensive study of temporal correlations between pollutants simultaneously available (i.e. $\mathrm{PM}_{10}$ was used as a proxy for $\mathrm{PM}_{2.5}$ and back smoke as a proxy for $\mathrm{PM}_{2.5}$ absorbance). We accounted for change of home address during the whole fetal period since the date of moving and new address was available. 


\section{Methods S2. Description of the causal mediation analysis}

The causal mediation analysis provides a better understanding of the causal chain by which an independent variable $(\mathrm{X})$ influences a dependent variable $(\mathrm{Y})$ through a mediator $(\mathrm{M})$. Consistent with its conceptual definition (3), this involves sequential testing of the following: i) the effect of the exposure (X) on the outcome (Y); ii) the effect of the exposure e (X) on the mediator (M); iii) the effect of the mediator $(\mathrm{M})$ on the outcome $(\mathrm{Y})$ controlling for the exposure $(\mathrm{X})$, and iv) the effect of the exposure $(\mathrm{X})$ on the outcome $(\mathrm{Y})$ controlling for the mediator $(\mathrm{M})$. The causal mediation analysis provides estimation of the natural direct effect (NDE), the natural indirect effect (NIE), and the total effect (3). The natural direct effect (NDE) expresses how much the outcome (Y) would change if the exposure (X) is set at a level $a=1$ to level $a=0$ but for each individual the mediator (M) is kept at the level it would have taken in the absence of the exposure. The natural indirect effect (NIE) expresses how much the outcome (Y) would change on average if the exposure (X) is controlled at level $a=1$, but the mediator (M) is changed from the level it would take if $a=0$ to the level it would take if $a=1$. The total effect can be defined as how much the outcome (Y) would change overall for a change in the exposure (X) from level $a=0$ to level $a=1$.

In our study, we applied causal mediation analysis to assess the direct and indirect effects of air pollution exposure during fetal life $(\mathrm{X})$ on cognitive function $(\mathrm{Y})$ where we tested whether part of the indirect effect was mediated by cortical thinness (M) (Figure S1). We used negative binomial regression for the outcome regression model and linear regression for the mediator regression model. Standard errors were calculated using bootstrapping. All models were adjusted for all potential confounding variables described in the section "Potential confounding variables" of the manuscript. The total effect results as the product of the natural direct effect (NDE) and natural indirect effect (NIE). We also calculated the proportion mediated as incidence rate ratio $(\mathrm{IRR})^{\mathrm{NDE}}\left(\mathrm{IRR}^{\mathrm{NIE}}-1\right) /\left(\mathrm{IRR}^{\mathrm{NDE}} \mathrm{IRR}^{\mathrm{NIE}}-1\right)$. 


\section{Methods S3. Cognitive function tests selected based on the identified regions}

In the first analysis, we found that higher particulate matter levels during fetal life were associated with thinner cortices in specific regions of the frontal, parietal and occipital brain regions (Table 3). Post-hoc, we went back to the literature to find out in which cognitive processes these regions were involved. The frontal brain regions and the (pre)cuneus are known to be involved in attention and executive functions $(4,5)$ while the fusiform gyrus is known to be involved in the face perception, object recognition, and memory (6). Therefore, we selected two specific tasks of the NEPSY-II test for the mediation analysis: the attention and executive functioning task and the memory for faces task.

\section{Attention and executive functioning task}

Children were assessed with two different tasks from the attention and executive functioning domain of the NEPSY-II: auditory attention task and response set task (7-9). The auditory attention task was administered first. It is designed to assess selective auditory attention and the ability to sustain it (vigilance). Selective attention refers to the ability to focus on a specific task while suppressing irrelevant stimuli. Sustained attention refers to the ability to attend to a task for a long(er) period of time. In the auditory attention task, the children were presented with recording of a long list of color words and other words and were asked to only respond to the word "red" by touching the red circle on the sheet in front of them. The sheet also contained a blue, black, and yellow circle, but these circles had to be ignored. Touching the red circle within two seconds indicated a correct response.

The response set task was then administered. This task taps into response inhibition and working memory. Inhibition is the ability to suppress (automatic) behavior. Working memory is required to keep information actively in mind for as long as needed to complete a task. In this task, children must respond to the word "red" by touching the yellow circle, respond to "yellow" 
by touching the red circle, and lastly, respond to the word "blue" by touching the blue circle. All of the other colors or words should be ignored. Touching the correct circle within two seconds indicates a correct response. Touching another color is incorrect, as is having delayed response (not within a 2 seconds interval).

For each task, four scores were calculated: total number of correct responses, total number of commission errors (i.e. the number of times that the child responded erroneously to a nontarget), total number of omission errors (i.e. the number of target to which the children failed to respond), and inhibition errors (i.e. the number of times that the child responded to a color word inappropriately; in other words, fails to inhibit an inappropriate response).

\section{Memory for faces task}

Children were assessed with two different tasks from the memory and learning domain of the NEPSY-II: memory for faces task and memory for faces delayed task (7-9). The memory for faces test is designed to assess encoding of facial features, as well as face discrimination and recognition. The child was first presented with multiple series of three faces and was asked to look closely at each face (for five seconds). The child was then provided with another set of three faces and was asked which face he or she had seen before. Immediate recall is the skill to retrieve information from memory immediately after learning.

The memory for faces delayed task is designed to assess long-term memory for faces. This task was assessed after a delay period of 15 to 25 minutes and measured the ability to retrieve information after a longer period of time.

For both tasks, all presented faces showed a neutral expression. A total correct score was calculated for both tasks. 


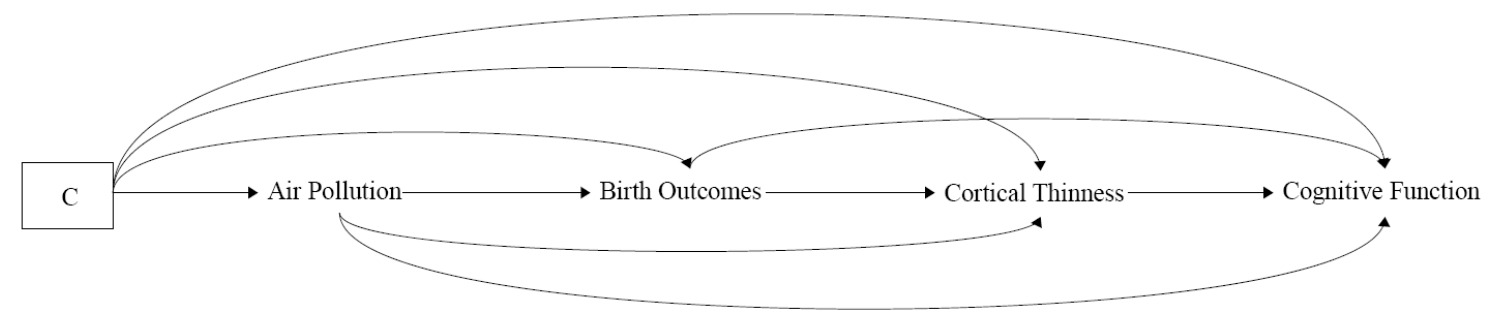

\section{Figure S1. Direct Acyclic Graph}

$\mathrm{C}$ denotes all the potential confounding variables in the relationship between air pollution exposure in fetal life and cognitive function in childhood, such as SES, parental lifestyle and ethnicity. This theoretical selection of confounders was reflected as completely as the data availability allowed. In our study we included: parental educational levels, monthly household income, parental countries of birth, parental ages, maternal prenatal smoking, maternal prenatal alcohol use, parental body mass indexes and heights, maternal parity, family status, maternal psychological distress, maternal intelligence quotient, and child genetic ancestry. Additionally, the models were adjusted for child's sex and child's age at the MRI session. The box indicates the conditioning on the potential confounders. Solid arrows represent existing pathways indicating thereby the direction of the associations. 
Table S1. Distribution of participant characteristics in observed and imputed datasets

\begin{tabular}{|c|c|c|c|}
\hline & Observed dataset $^{\mathrm{a}}$ & Imputed datasets $^{\mathrm{a}}$ & \% data imputed \\
\hline Maternal education level & & & 2.8 \\
\hline Primary education & 7.0 & 7.4 & \\
\hline Secondary education & 44.8 & 45.1 & \\
\hline University education & 48.2 & 47.4 & \\
\hline Paternal education level & & & 26.6 \\
\hline Primary education & 5.7 & 9.2 & \\
\hline Secondary education & 40.9 & 43.9 & \\
\hline University education & 53.4 & 46.9 & \\
\hline Monthly household income & & & 10.6 \\
\hline$<1,200 €$ & 14.1 & 15.8 & \\
\hline $1,200 €-2,000 €$ & 17.7 & 18.4 & \\
\hline$>2,000 €$ & 68.1 & 65.8 & \\
\hline Maternal country of birth & & & 1.4 \\
\hline The Netherlands & 65.2 & 64.7 & \\
\hline Cape Verde & 4.7 & 4.8 & \\
\hline Morocco & 4.7 & 4.8 & \\
\hline Surinam & 6.5 & 6.6 & \\
\hline Turkey & 4.5 & 4.7 & \\
\hline Other country of birth & 14.5 & 14.5 & \\
\hline Paternal country of birth & & & 20.8 \\
\hline The Netherlands & 72.7 & 66.3 & \\
\hline Cape Verde & 2.6 & 4.2 & \\
\hline Morocco & 1.9 & 3.1 & \\
\hline Surinam & 5.0 & 6.7 & \\
\hline Turkey & 3.4 & 4.9 & \\
\hline Other country of birth & 14.4 & 14.8 & \\
\hline Maternal age (years) & --- & --- & 0.0 \\
\hline Paternal age (years) & $32.9(5.3)$ & $32.8 \quad(5.5)$ & 18.3 \\
\hline Family status (mono vs. biparental) & 13.5 & 13.9 & 2.8 \\
\hline Maternal parity (multi vs. nulliparous) & 39.5 & 39.4 & 0.4 \\
\hline Maternal smoking use during pregnancy & & & 7.2 \\
\hline Never & 75.4 & 74.8 & \\
\hline Smoking use until pregnancy known & 6.5 & 6.6 & \\
\hline Continued smoking use during pregnancy & 18.1 & 18.6 & \\
\hline Maternal alcohol use during pregnancy & & & 6.9 \\
\hline Never & 37.6 & 38.0 & \\
\hline Alcohol use until pregnancy known & 14.3 & 14.3 & \\
\hline Continued alcohol use during pregnancy & 48.1 & 47.7 & \\
\hline Maternal pre-pregnancy body mass index $\left(\mathrm{kg} / \mathrm{m}^{2}\right)$ & --- & --- & 0.0 \\
\hline Paternal pre-pregnancy body mass index $\left(\mathrm{kg} / \mathrm{m}^{2}\right)$ & $25.3(3.3)$ & $25.3(3.4)$ & 18.3 \\
\hline Maternal height $(\mathrm{cm})$ & --- & --- & 0.0 \\
\hline Paternal height $(\mathrm{cm})$ & $182.9(7.3)$ & $182.3(7.5)$ & 18.3 \\
\hline Maternal overall psychological distress & $0.3(0.4)$ & $0.3(0.4)$ & 12.1 \\
\hline Maternal intelligence quotient score & $98.4(13.9)$ & $98.1(13.9)$ & 5.4 \\
\hline
\end{tabular}

${ }^{a}$ Values are percentages for the categorical variables and mean (standard deviation) for the continuous variables 
Table S2. Comparison of participant characteristics between included and not included subjects in the study among the 1,932 subjects selected for the MRI sub-study

\begin{tabular}{|c|c|c|c|c|}
\hline & $\begin{array}{c}\text { Included }^{2} \\
(\mathbf{n}=783)\end{array}$ & & $\begin{array}{c}\text { Not included }^{a} \\
(n=1,149)\end{array}$ & P value $^{b}$ \\
\hline Maternal education level & & & & $<.001$ \\
\hline Primary education & 7.0 & & 11.0 & \\
\hline Secondary education & 44.8 & & 50.5 & \\
\hline University education & 48.2 & & 38.5 & \\
\hline Paternal education level & & & & .006 \\
\hline Primary education & 5.7 & & 8.5 & \\
\hline Secondary education & 40.9 & & 46.4 & \\
\hline University education & 53.4 & & 45.1 & \\
\hline Monthly Household income & & & & .001 \\
\hline$<1,200 €$ & 14.1 & & 19.5 & \\
\hline $1,200 €-2,000 €$ & 17.7 & & 21.3 & \\
\hline$>2,000 €$ & 68.1 & & 59.2 & \\
\hline Maternal country of birth & & & & $<.001$ \\
\hline The Netherlands & 65.2 & & 53.9 & \\
\hline Cape Verde & 4.7 & & 4.8 & \\
\hline Morocco & 4.7 & & 4.8 & \\
\hline Surinam & 6.5 & & 7.8 & \\
\hline Turkey & 4.5 & & 9.0 & \\
\hline Other country of birth & 14.5 & & 19.7 & \\
\hline Paternal country of birth & & & & .02 \\
\hline The Netherlands & 72.7 & & 66.2 & \\
\hline Cape Verde & 2.6 & & 2.7 & \\
\hline Morocco & 1.9 & & 3.5 & \\
\hline Surinam & 5.0 & & 6.3 & \\
\hline Turkey & 3.4 & & 6.7 & \\
\hline Other country of birth & 14.4 & & 14.5 & \\
\hline Maternal age (years) & 30.7 & (4.9) & $29.6(5.2)$ & $<.001$ \\
\hline Paternal age (years) & 32.9 & (5.3) & $32.7 \quad(5.8)$ & .42 \\
\hline Family status (mono $v s \cdot$ biparental) & 13.5 & & 15.8 & .18 \\
\hline Maternal parity (multi $v s \cdot$ nulliparous) & 39.5 & & 40.3 & .87 \\
\hline Maternal smoking use during pregnancy & & & & .02 \\
\hline Never & 75.4 & & 69.1 & \\
\hline Smoking use until pregnancy known & 6.5 & & 7.9 & \\
\hline Continued smoking use during pregnancy & 18.2 & & 22.9 & \\
\hline Maternal alcohol use during pregnancy & & & & $<.001$ \\
\hline Never & 37.6 & & 46.6 & \\
\hline Alcohol use until pregnancy known & 14.3 & & 15.0 & \\
\hline Continued alcohol use during pregnancy & 48.1 & & 38.3 & \\
\hline Maternal pre-pregnancy body mass index $\left(\mathrm{kg} / \mathrm{m}^{2}\right)$ & 24.6 & $(4.3)$ & $24.9(4.6)$ & .23 \\
\hline Paternal pre-pregnancy body mass index $\left(\mathrm{kg} / \mathrm{m}^{2}\right)$ & 25.3 & $(3.3)$ & $25.1(3.5)$ & .25 \\
\hline Maternal height $(\mathrm{cm})$ & 168.6 & (7.4) & $167.7(7.5)$ & .01 \\
\hline Paternal height $(\mathrm{cm})$ & 182.9 & $(7.3)$ & $181.9(8.1)$ & .02 \\
\hline Maternal overall psychological distress & 0.3 & $(0.4)$ & $0.4(0.5)$ & $<.001$ \\
\hline Maternal intelligence quotient score & 98.4 & $(13.9)$ & $94.2(14.7)$ & $<.001$ \\
\hline
\end{tabular}

${ }^{a}$ Values are percentages for the categorical variables and mean (standard deviation) for the continuous variables. ${ }^{\mathrm{b}} \chi^{2}$ test for categorical variables and $\mathrm{t}$-student test for continuous variables 
Table S3. Comparison of participant characteristics between included and not included subjects in the study among the 8,879 subjects recruited in the full cohort in pregnancy

\begin{tabular}{|c|c|c|c|c|}
\hline & $\begin{array}{c}\begin{array}{c}\text { Included } \\
(n=783)\end{array} \\
\end{array}$ & & $\begin{array}{c}\text { Not included }^{\mathbf{a}} \\
(\mathrm{n}=\mathbf{8 , 0 9 7})\end{array}$ & P value $^{\mathrm{b}}$ \\
\hline Maternal education level & & & & $<.001$ \\
\hline Primary education & 7.0 & & 12.1 & \\
\hline Secondary education & 44.8 & & 46.6 & \\
\hline University education & 48.2 & & 41.3 & \\
\hline Paternal education level & & & & .05 \\
\hline Primary education & 5.7 & & 8.6 & \\
\hline Secondary education & 40.9 & & 41.1 & \\
\hline University education & 53.4 & & 50.3 & \\
\hline Monthly Household income & & & & $<.001$ \\
\hline$<1,200 €$ & 14.1 & & 21.6 & \\
\hline $1,200 €-2,000 €$ & 17.7 & & 18.7 & \\
\hline$>2,000 €$ & 68.1 & & 59.7 & \\
\hline Maternal country of birth & & & & $<.001$ \\
\hline The Netherlands & 65.2 & & 47.8 & \\
\hline Cape Verde & 4.7 & & 4.1 & \\
\hline Morocco & 4.7 & & 6.9 & \\
\hline Surinam & 6.5 & & 9.3 & \\
\hline Turkey & 4.5 & & 9.6 & \\
\hline Other country of birth & 14.5 & & 22.3 & \\
\hline Paternal country of birth & & & & $<.001$ \\
\hline The Netherlands & 72.7 & & 60.2 & \\
\hline Cape Verde & 2.6 & & 2.5 & \\
\hline Morocco & 1.9 & & 4.5 & \\
\hline Surinam & 5.0 & & 7.0 & \\
\hline Turkey & 3.4 & & 7.2 & \\
\hline Other country of birth & 14.4 & & 18.5 & \\
\hline Maternal age (years) & 30.7 & $(4.9)$ & $29.5(5.3)$ & $<.001$ \\
\hline Paternal age (years) & 32.9 & (5.3) & $32.7 \quad(5.8)$ & .30 \\
\hline Family status (mono $v s \cdot$ biparental) & 13.5 & & 14.9 & .30 \\
\hline Maternal parity (multi $v s \cdot$ nulliparous) & 39.5 & & 44.9 & .005 \\
\hline Maternal smoking use during pregnancy & & & & .14 \\
\hline Never & 75.4 & & 74.4 & \\
\hline Smoking use until pregnancy known & 6.5 & & 8.5 & \\
\hline Continued smoking use during pregnancy & 18.1 & & 17.1 & \\
\hline Maternal alcohol use during pregnancy & & & & $<.001$ \\
\hline Never & 37.6 & & 51.2 & \\
\hline Alcohol use until pregnancy known & 14.3 & & 13.6 & \\
\hline Continued alcohol use during pregnancy & 48.1 & & 35.2 & \\
\hline Maternal pre-pregnancy body mass index $\left(\mathrm{kg} / \mathrm{m}^{2}\right)$ & 24.6 & $(4.3)$ & $24.9(4.6)$ & .08 \\
\hline Paternal pre-pregnancy body mass index $\left(\mathrm{kg} / \mathrm{m}^{2}\right)$ & 25.3 & (3.3) & $25.3(3.5)$ & 0.78 \\
\hline Maternal height $(\mathrm{cm})$ & 168.6 & (7.4) & 167 (7.4) & $<.001$ \\
\hline Paternal height $(\mathrm{cm})$ & 182.9 & (7.3) & $181.4(8.0)$ & $<.001$ \\
\hline Maternal overall psychological distress & 0.3 & $(0.4)$ & $0.3(0.4)$ & .24 \\
\hline Maternal intelligence quotient score & 98.4 & (13.9) & $95.3(15.5)$ & $<.001$ \\
\hline
\end{tabular}

${ }^{a}$ Values are percentages for the categorical variables and mean (standard deviation) for the continuous variables. ${ }^{\mathrm{b}} \chi^{2}$ test for categorical variables and $\mathrm{t}$-student test for continuous variables 
Table S4. Global brain volume measures (in $\mathrm{mm}$ ) in children at 6-10 years of age

\begin{tabular}{|c|c|c|c|c|c|c|c|}
\hline & Mean & (SD) & Minimum & $\begin{array}{c}\text { Percentile } \\
25\end{array}$ & Median & $\begin{array}{l}\text { Percentile } \\
75\end{array}$ & Maximum \\
\hline Total brain volume & 1146063 & $(121154)$ & 709551 & 1062833 & 1141372 & 1227930 & 1549471 \\
\hline $\begin{array}{l}\text { Cortical gray matter } \\
\text { volume }\end{array}$ & 551350 & $(65306)$ & 300283 & 508679 & 551737 & 597360 & 746402 \\
\hline $\begin{array}{l}\text { Cortical white matter } \\
\text { volume }\end{array}$ & 381212 & $(47090)$ & 227365 & 347471 & 379598 & 412231 & 565693 \\
\hline $\begin{array}{l}\text { Subcortical gray } \\
\text { matter volume }\end{array}$ & 61961 & $(4940)$ & 45762 & 58555 & 61801 & 65086 & 77729 \\
\hline Ventricular volume & 11119 & $(5045)$ & 3752 & 7700 & 9871 & 13240 & 39891 \\
\hline
\end{tabular}


Table S5. Spearman correlations between air pollution levels during fetal life

\begin{tabular}{lcccc}
\hline & $\mathrm{NO}_{2}$ & $\begin{array}{c}\text { Fine } \\
\text { particles }\end{array}$ & $\begin{array}{c}\text { Coarse } \\
\text { particles }\end{array}$ & $\begin{array}{c}\text { Absorbance of } \\
\text { fine particles }\end{array}$ \\
\hline $\mathrm{NO}_{2}$ & 1.00 & & & \\
Fine particles & 0.43 & 1.00 & & \\
Coarse particles & 0.66 & 0.68 & 1.00 & \\
Absorbance of fine particles & 0.79 & 0.69 & 0.75 & 1.00 \\
\hline
\end{tabular}
Abbreviation: $\mathrm{NO}_{2}$, nitrogen dioxide 
Table S6. Participant characteristics according to $\mathrm{NO}_{2}$ levels during fetal life

\begin{tabular}{|c|c|c|c|c|}
\hline & \multicolumn{3}{|c|}{$\mathrm{NO}_{2}$ levels $\left(\mu \mathrm{g} / \mathrm{m}^{3}\right)$} & \multirow[b]{2}{*}{ P Value $^{\mathbf{b}}$} \\
\hline & Low $(<37.1)^{\mathrm{a}}$ & Medium (37.1-41.7) & High $(>41.7)^{\mathrm{a}}$ & \\
\hline Maternal education level & & & & .24 \\
\hline Primary education & 7.8 & 8.7 & 4.4 & \\
\hline Secondary education & 47.3 & 43.3 & 43.8 & \\
\hline University education & 44.9 & 48.0 & 51.8 & \\
\hline Paternal education level & & & & .02 \\
\hline Primary education & 4.1 & 10.2 & 3.0 & \\
\hline Secondary education & 44.3 & 36.0 & 42.2 & \\
\hline University education & 51.6 & 53.8 & 54.8 & \\
\hline Monthly household income & & & & .13 \\
\hline$<1,200 €$ & 16.5 & 16.5 & 9.4 & \\
\hline $1,200 €-2,000 €$ & 16.5 & 19.0 & 17.6 & \\
\hline$>2,000 €$ & 67.0 & 64.6 & 73.0 & \\
\hline Maternal country of birth & & & & .24 \\
\hline The Netherlands & 69.0 & 58.5 & 68.0 & \\
\hline Cape Verde & 5.4 & 6.6 & 2.0 & \\
\hline Morocco & 4.3 & 6.2 & 3.5 & \\
\hline Surinam & 6.2 & 6.6 & 6.6 & \\
\hline Turkey & 3.5 & 4.7 & 5.5 & \\
\hline Other country of birth & 11.6 & 17.4 & 14.5 & \\
\hline Paternal country of birth & & & & .55 \\
\hline The Netherlands & 76.0 & 63.4 & 78.7 & \\
\hline Cape Verde & 2.9 & 3.4 & 1.4 & \\
\hline Morocco & 1.5 & 3.4 & 0.9 & \\
\hline Surinam & 6.4 & 6.4 & 2.4 & \\
\hline Turkey & 2.9 & 3.9 & 3.3 & \\
\hline Other country of birth & 10.3 & 19.5 & 13.3 & \\
\hline Maternal age (years) & $30.3(5.0)$ & $30.6(5.2)$ & $31.3(4.6)$ & .04 \\
\hline Paternal age (years) & $32.9(5.3)$ & $32.8(5.4)$ & $33.1 \quad(5.2)$ & .89 \\
\hline Family status (mono vs. biparental) & 13.0 & 14.4 & 13.1 & .88 \\
\hline Maternal parity (multi $v s$. nulliparous) & 39.8 & 41.2 & 37.5 & .90 \\
\hline Maternal smoking use during pregnancy & & & & .83 \\
\hline Never & 77.3 & 75.3 & 73.4 & \\
\hline Smoking use until pregnancy known & 6.1 & 5.8 & 7.6 & \\
\hline Continued smoking use during pregnancy & 16.6 & 18.9 & 19.0 & \\
\hline Maternal alcohol use during pregnancy & & & & .48 \\
\hline Never & 39.3 & 36.9 & 36.6 & \\
\hline Alcohol use until pregnancy known & 11.3 & 14.3 & 17.2 & \\
\hline Continued alcohol use during pregnancy & 49.4 & 48.8 & 46.2 & \\
\hline Maternal pre-pregnancy BMI $\left(\mathrm{kg} / \mathrm{m}^{2}\right)$ & $24.7 \quad(4.4)$ & $24.7 \quad(4.4)$ & 24.5 & .84 \\
\hline Paternal pre-pregnancy BMI $\left(\mathrm{kg} / \mathrm{m}^{2}\right)$ & $25.7(3.4)$ & $25.3(3.5)$ & $25.0 \quad(3.2)$ & .11 \\
\hline Maternal height $(\mathrm{cm})$ & $169.4(6.9)$ & $167.6(7.4)$ & $168.7(7.7)$ & .03 \\
\hline Paternal height $(\mathrm{cm})$ & $183.5(7.2)$ & $182.1(7.9)$ & $182.9(6.7)$ & .12 \\
\hline Maternal overall psychological distress & $0.3(0.3)$ & $0.3(0.5)$ & $0.3(0.4)$ & .16 \\
\hline Maternal intelligence quotient score & 98.8 (14.2) & $97.6(13.5)$ & $98.7(13.8)$ & .55 \\
\hline
\end{tabular}

Abbreviation: BMI, body mass index; NO2, nitrogen dioxide.

${ }^{a}$ Values are percentages for the categorical variables and mean (standard deviation) for the continuous variables.

${ }^{\mathrm{b}} \chi^{2}$ test for categorical variables and one-way ANOVA test for continuous variables 
Table S7. Participant characteristics according to fine particles levels during fetal life

\begin{tabular}{|c|c|c|c|c|}
\hline & \multicolumn{3}{|c|}{ Fine particles levels $\left(\mu \mathrm{g} / \mathrm{m}^{3}\right)$} & \multirow[b]{2}{*}{ P Value ${ }^{\text {b }}$} \\
\hline & $\begin{array}{c}\text { Low } \\
(<19.7)^{\mathrm{a}}\end{array}$ & $\begin{array}{c}\text { Medium } \\
(19.7-21.0)^{\mathrm{a}} \\
\end{array}$ & $\begin{array}{c}\text { High } \\
(>\mathbf{2 1 . 0})^{\mathrm{a}}\end{array}$ & \\
\hline Maternal education level & & & & .05 \\
\hline Primary education & 10.8 & 5.1 & 5.1 & \\
\hline Secondary education & 41.4 & 44.4 & 48.6 & \\
\hline University education & 47.8 & 50.6 & 46.2 & \\
\hline Paternal education level & & & & .41 \\
\hline Primary education & 8.0 & 3.6 & 5.7 & \\
\hline Secondary education & 38.0 & 42.0 & 42.5 & \\
\hline University education & 54.0 & 54.4 & 51.8 & \\
\hline Monthly household income & & & & .003 \\
\hline$<1,200 €$ & 20.7 & 13.0 & 8.7 & \\
\hline $1,200 €-2,000 €$ & 13.8 & 18.0 & 21.4 & \\
\hline$>2,000 €$ & 65.5 & 69.0 & 69.9 & \\
\hline Maternal country of birth & & & & .18 \\
\hline The Netherlands & 64.5 & 64.5 & 66.5 & \\
\hline Cape Verde & 7.8 & 3.5 & 2.7 & \\
\hline Morocco & 5.1 & 5.0 & 3.9 & \\
\hline Surinam & 7.0 & 7.3 & 5.1 & \\
\hline Turkey & 3.9 & 5.4 & 4.3 & \\
\hline Other country of birth & 11.7 & 14.3 & 17.5 & \\
\hline Paternal country of birth & & & & .25 \\
\hline The Netherlands & 69.9 & 73.5 & 74.7 & \\
\hline Cape Verde & 6.0 & 0.5 & 1.4 & \\
\hline Morocco & 1.0 & 3.0 & 1.8 & \\
\hline Surinam & 6.5 & 4.4 & 4.1 & \\
\hline Turkey & 4.0 & 3.4 & 2.8 & \\
\hline Other country of birth & 12.6 & 15.2 & 15.2 & \\
\hline Maternal age (years) & $30.9(5.1)$ & $30.8(4.9)$ & $30.5(4.8)$ & .57 \\
\hline Paternal age (years) & $33.1 \quad(5.2)$ & $33.0(5.2)$ & $32.7(5.5)$ & .79 \\
\hline Family status (mono $v s$. biparental) & 15.6 & 12.8 & 12.2 & .50 \\
\hline Maternal parity (multi vs. nulliparous) & 42.4 & 35.0 & 40.9 & .03 \\
\hline Maternal smoking use during pregnancy & & & & .011 \\
\hline Never & 74.6 & 77.9 & 73.7 & \\
\hline Smoking use until pregnancy known & 10.2 & 5.8 & 3.6 & \\
\hline Continued smoking use during pregnancy & 15.2 & 16.3 & 22.7 & \\
\hline Maternal alcohol use during pregnancy & & & & .15 \\
\hline Never & 36.3 & 38.0 & 38.4 & \\
\hline Alcohol use until pregnancy known & 10.1 & 15.7 & 16.8 & \\
\hline Continued alcohol use during pregnancy & 53.6 & 46.3 & 44.8 & \\
\hline Maternal pre-pregnancy body mass index $\left(\mathrm{kg} / \mathrm{m}^{2}\right)$ & $24.5(4.4)$ & $24.6(4.3)$ & $24.8(4.2)$ & .66 \\
\hline Paternal pre-pregnancy body mass index $\left(\mathrm{kg} / \mathrm{m}^{2}\right)$ & $25.8(3.5)$ & $25.0(3.2)$ & $25.2(3.3)$ & .07 \\
\hline Maternal height $(\mathrm{cm})$ & $168.1(7.2)$ & $168.6(7.4)$ & $168.9(7.6)$ & .45 \\
\hline Paternal height $(\mathrm{cm})$ & $182.7(6.6)$ & $182.9(7.6)$ & $183.0(7.6)$ & .87 \\
\hline Maternal overall psychological distress & $0.3(0.4)$ & $0.3(0.4)$ & $0.3(0.4)$ & .61 \\
\hline Maternal intelligence quotient score & $98.4(15.0)$ & $98.8(13.5)$ & $97.9(13.1)$ & .77 \\
\hline
\end{tabular}

${ }^{a}$ Values are percentages for the categorical variables and mean (standard deviation) for the continuous variables.

${ }^{\mathrm{b}} \chi^{2}$ test for categorical variables and one-way ANOVA test for continuous variables 
Table S8. Participant characteristics according to coarse particles levels during fetal life

\begin{tabular}{|c|c|c|c|c|}
\hline & \multicolumn{3}{|c|}{ Coarse particles levels $\left(\mu \mathrm{g} / \mathrm{m}^{3}\right)$} & \multirow[b]{2}{*}{ P Value $^{\text {b }}$} \\
\hline & $\begin{array}{c}\text { Low } \\
(<11.3)^{\mathrm{a}}\end{array}$ & $\begin{array}{c}\text { Medium } \\
(11.3-12.4)^{\mathrm{a}}\end{array}$ & $\begin{array}{c}\text { High } \\
(>12.4)^{\mathrm{a}}\end{array}$ & \\
\hline Maternal education level & & & & .04 \\
\hline Primary education & 10.2 & 6.3 & 4.3 & \\
\hline Secondary education & 43.9 & 48.6 & 41.9 & \\
\hline University education & 45.9 & 45.1 & 53.8 & \\
\hline Paternal education level & & & & .27 \\
\hline Primary education & 8.5 & 4.9 & 3.9 & \\
\hline Secondary education & 40.2 & 43.7 & 38.9 & \\
\hline University education & 51.3 & 51.4 & 57.2 & \\
\hline Monthly household income & & & & $<.001$ \\
\hline$<1,200 €$ & 21.1 & 16.0 & 5.5 & \\
\hline $1,200 €-2,000 €$ & 17.2 & 18.2 & 17.7 & \\
\hline$>2,000 €$ & 61.6 & 65.8 & 76.8 & \\
\hline Maternal country of birth & & & & .007 \\
\hline The Netherlands & 65.0 & 60.3 & 70.2 & \\
\hline Cape Verde & 7.0 & 5.1 & 1.9 & \\
\hline Morocco & 4.3 & 7.4 & 2.3 & \\
\hline Surinam & 6.6 & 8.2 & 4.7 & \\
\hline Turkey & 4.7 & 5.4 & 3.5 & \\
\hline Other country of birth & 12.5 & 13.6 & 17.4 & \\
\hline Paternal country of birth & & & & .008 \\
\hline The Netherlands & 69.7 & 72.6 & 75.7 & \\
\hline Cape Verde & 5.0 & 2.0 & 0.9 & \\
\hline Morocco & 2.0 & 3.0 & 0.9 & \\
\hline Surinam & 6.5 & 7.6 & 1.4 & \\
\hline Turkey & 3.5 & 4.6 & 2.3 & \\
\hline Other country of birth & 13.3 & 10.2 & 18.8 & \\
\hline Maternal age (years) & $30.3(5.1)$ & $30.8(5.2)$ & $31.0(4.4)$ & .28 \\
\hline Paternal age (years) & $32.7(5.6)$ & $33.2(5.4)$ & $33.0(5.0)$ & .67 \\
\hline Family status (mono vs. biparental) & 16.1 & 13.9 & 10.6 & .19 \\
\hline Maternal parity (multi vs. nulliparous) & 39.1 & 42.5 & 36.9 & 61 \\
\hline Maternal smoking use during pregnancy & & & & .007 \\
\hline Never & 72.4 & 79.2 & 74.6 & \\
\hline Smoking use until pregnancy known & 10.7 & 5.1 & 3.6 & \\
\hline Continued smoking use during pregnancy & 16.9 & 15.7 & 21.8 & \\
\hline Maternal alcohol use during pregnancy & & & & .08 \\
\hline Never & 39.3 & 41.1 & 32.5 & \\
\hline Alcohol use until pregnancy known & 11.9 & 11.9 & 18.9 & \\
\hline Continued alcohol use during pregnancy & 48.8 & 47.0 & 48.6 & \\
\hline Maternal pre-pregnancy body mass index $\left(\mathrm{kg} / \mathrm{m}^{2}\right)$ & $24.3(4.0)$ & $25.1(4.7)$ & $24.6(4.1)$ & .09 \\
\hline Paternal pre-pregnancy body mass index $\left(\mathrm{kg} / \mathrm{m}^{2}\right)$ & $25.4(3.4)$ & $25.2(3.5)$ & $25.4(3.1)$ & .87 \\
\hline Maternal height (cm) & $168.7(7.5)$ & $168.4(7.0)$ & $168.5(7.6)$ & .89 \\
\hline Paternal height (cm) & $182.8(6.9)$ & 183.0 & $182.9(7.4)$ & .96 \\
\hline Maternal overall psychological distress & $0.3 \quad(0.4)$ & $0.3(0.4)$ & $0.3 \quad(0.4)$ & .39 \\
\hline Maternal intelligence quotient score & $98.6(14.5)$ & $98.0(14.0)$ & $98.5(13.2)$ & .88 \\
\hline
\end{tabular}

${ }^{a}$ Values are percentages for the categorical variables and mean (standard deviation) for the continuous variables.

${ }^{\mathrm{b}} \chi^{2}$ test for categorical variables and one-way ANOVA test for continuous variables 
Table S9. Participant characteristics according to absorbance of fine particles levels during fetal life

\begin{tabular}{|c|c|c|c|c|}
\hline & \multicolumn{3}{|c|}{ Absorbance of fine particles levels $\left(\mu \mathrm{g} / \mathrm{m}^{3}\right)$} & \multirow[b]{2}{*}{ P Value ${ }^{\text {b }}$} \\
\hline & Low $(<1.8)^{\mathrm{a}}$ & Medium (1.8-2.0) ${ }^{\mathrm{a}}$ & High $(>2.0)^{a}$ & \\
\hline Maternal education level & & & & .16 \\
\hline Primary education & 9.1 & 7.4 & 4.4 & \\
\hline Secondary education & 47.2 & 41.8 & 45.4 & \\
\hline University education & 43.7 & 50.8 & 50.2 & \\
\hline Paternal education level & & & & .40 \\
\hline Primary education & 7.9 & 3.8 & 5.5 & \\
\hline Secondary education & 38.9 & 44.6 & 39.2 & \\
\hline University education & 53.2 & 51.6 & 55.3 & \\
\hline Monthly household income & & & & .08 \\
\hline$<1,200 €$ & 18.6 & 14.1 & 9.8 & \\
\hline $1,200 €-2,000 €$ & 18.2 & 17.9 & 17.0 & \\
\hline$>2,000 €$ & 63.2 & 67.9 & 73.2 & \\
\hline Maternal country of birth & & & & .08 \\
\hline The Netherlands & 63.4 & 65.3 & 66.8 & \\
\hline Cape Verde & 7.0 & 3.9 & 3.1 & \\
\hline Morocco & 6.6 & 4.6 & 2.7 & \\
\hline Surinam & 8.6 & 5.4 & 5.5 & \\
\hline Turkey & 2.7 & 5.8 & 5.1 & \\
\hline Other country of birth & 11.7 & 15.1 & 16.8 & \\
\hline Paternal country of birth & & & & .31 \\
\hline The Netherlands & 70.8 & 73.1 & 74.2 & \\
\hline Cape Verde & 4.5 & 1.5 & 1.8 & \\
\hline Morocco & 2.5 & 2.0 & 1.4 & \\
\hline Surinam & 6.9 & 5.0 & 3.2 & \\
\hline Turkey & 3.5 & 2.5 & 4.2 & \\
\hline Other country of birth & 11.8 & 15.9 & 15.2 & \\
\hline Maternal age (years) & $30.1 \quad(5.1)$ & $31.2(4.8)$ & $30.8 \quad(4.8)$ & .04 \\
\hline Paternal age (years) & $32.7 \quad(5.1)$ & $33.0 \quad(5.7)$ & $33.1 \quad(5.2)$ & .75 \\
\hline Family status (mono vs. biparental) & 14.2 & 14.1 & 12.3 & .78 \\
\hline Maternal parity (multi vs. nulliparous) & 40.4 & 41.9 & 36.2 & .30 \\
\hline Maternal smoking use during pregnancy & & & & .25 \\
\hline Never & 77.8 & 76.1 & 72.2 & \\
\hline Smoking use until pregnancy known & 7.8 & 5.8 & 5.8 & \\
\hline Continued smoking use during pregnancy & 14.4 & 18.1 & 22.0 & \\
\hline Maternal alcohol use during pregnancy & & & & .33 \\
\hline Never & 39.5 & 34.8 & 38.4 & \\
\hline Alcohol use until pregnancy known & 10.7 & 16.0 & 16.1 & \\
\hline Continued alcohol use during pregnancy & 49.8 & 49.2 & 45.5 & \\
\hline Maternal pre-pregnancy body mass index $\left(\mathrm{kg} / \mathrm{m}^{2}\right)$ & $24.8(4.4)$ & $24.7(4.6)$ & $24.4(3.9)$ & .58 \\
\hline Paternal pre-pregnancy body mass index $\left(\mathrm{kg} / \mathrm{m}^{2}\right)$ & $25.5(3.4)$ & $25.0 \quad(3.2)$ & $25.5(3.4)$ & .28 \\
\hline Maternal height (cm) & $168.5(7.2)$ & $168.1(7.0)$ & $169.1 \quad(7.9)$ & .32 \\
\hline Paternal height $(\mathrm{cm})$ & $182.7(7.1)$ & $183.1(7.4)$ & $182.8(7.5)$ & .84 \\
\hline Maternal overall psychological distress & $0.3(0.5)$ & $0.3(0.4)$ & $0.3(0.4)$ & .12 \\
\hline Maternal intelligence quotient score & $98.5(14.8)$ & $98.3(13.2)$ & $98.3(13.6)$ & .99 \\
\hline
\end{tabular}

${ }^{a}$ Values are percentages for the categorical variables and mean (standard deviation) for the continuous variables. ${ }^{\mathrm{b}} \chi^{2}$ test for categorical variables and one-way ANOVA test for continuous variables 
Table S10. Thickness (in $\mathrm{mm}$ ) of the identified thinner brain regions in relation to higher exposure to air pollution during fetal life

\begin{tabular}{|c|c|c|c|c|c|c|c|c|c|}
\hline & Hemisphere & $\begin{array}{c}\text { Size } \\
\left(\mathbf{m m}^{2}\right)\end{array}$ & Mean & (SD) & Minimum & $\begin{array}{l}\text { Percentile } \\
25\end{array}$ & Median & $\begin{array}{c}\text { Percentile } \\
75\end{array}$ & Maximum \\
\hline Precuneus region & Right & 936 & 3.14 & $(0.32)$ & 1.61 & 3.01 & 3.22 & 3.36 & 3.97 \\
\hline Pars opercularis region & Right & 753 & 3.00 & $(0.19)$ & 2.23 & 2.88 & 3.02 & 3.14 & 3.46 \\
\hline Pars orbitalis region & Right & 651 & 2.92 & $(0.30)$ & 2.02 & 2.73 & 2.93 & 3.12 & 3.71 \\
\hline Rostral middle frontal region & Right & 2995 & 2.73 & $(0.22)$ & 2.00 & 2.60 & 2.76 & 2.89 & 3.23 \\
\hline Superior frontal region & Right & 722 & 2.63 & $(0.27)$ & 1.85 & 2.43 & 2.65 & 2.83 & 3.31 \\
\hline Cuneus region & Left & 843 & 2.31 & $(0.25)$ & 1.67 & 2.14 & 2.29 & 2.46 & 3.28 \\
\hline Lateral orbitofrontal region & Right & 565 & 2.82 & $(0.33)$ & 1.86 & 2.59 & 2.83 & 3.06 & 3.88 \\
\hline Fusiform region & Left & 532 & 2.37 & $(0.24)$ & 1.62 & 2.21 & 2.37 & 2.51 & 3.42 \\
\hline
\end{tabular}

Abbreviations: SD, standard deviation 
Table S11. Adjusted association between air pollution exposure during fetal life and cortical thickness (in $\mathrm{mm}$ ) at 6-10 years of age restricting to those children without attention deficit hyperactivity, pervasive developmental, dysregulation, and aggressive problems

\begin{tabular}{|c|c|c|c|c|c|}
\hline & Hemisphere & $\begin{array}{c}\text { Size brain } \\
\text { region }\left(\mathrm{mm}^{2}\right)\end{array}$ & Coef. & $(95 \% \mathrm{CI})^{\mathrm{a}}$ & P value \\
\hline \multicolumn{6}{|l|}{ Fine particles exposure } \\
\hline Precuneus region & Right & 936 & -0.045 & $(-0.062$ to -0.028$)$ & $<.001$ \\
\hline Pars opercularis region & Right & 753 & -0.024 & $(-0.033$ to -0.014$)$ & $<.001$ \\
\hline Pars orbitalis region & Right & 651 & -0.028 & $(-0.043$ to -0.012$)$ & .001 \\
\hline Rostral middle frontal region & Right & 2,995 & -0.029 & $(-0.041$ to -0.018$)$ & $<.001$ \\
\hline Superior frontal region & Right & 722 & -0.029 & $(-0.043$ to -0.016$)$ & $<.001$ \\
\hline Cuneus region & Left & 843 & -0.022 & $(-0.035$ to -0.009$)$ & .002 \\
\hline \multicolumn{6}{|l|}{ Coarse particles exposure } \\
\hline Lateral orbitofrontal region & Right & 565 & -0.037 & $(-0.059$ to -0.016$)$ & .001 \\
\hline \multicolumn{6}{|l|}{ Absorbance particles exposure } \\
\hline Fusiform region & Left & 532 & -0.105 & $(-0.160$ to -0.049$)$ & $<.001$ \\
\hline
\end{tabular}

Abbreviations: CI, confidence interval; Coef, beta coefficient.

${ }^{a}$ Beta coefficient (95\% Confidence Interval) from linear regression model adjusted for parental educational levels, monthly household income, parental countries of birth, parental ages, maternal prenatal smoking, maternal prenatal alcohol use, parental body mass indexes and heights, maternal parity, family status, maternal psychological distress, maternal intelligence quotient, and child sex, age, and genetic ancestry. Coefficients represent the differences in thickness $(\mathrm{mm})$ per each increase of $5 \mu \mathrm{g} / \mathrm{m}^{3}$ of fine particles, $5 \mu \mathrm{g} / \mathrm{m}^{3}$ of coarse particles, and $10^{-5} \mathrm{~m}^{-}$ ${ }^{1}$ of absorbance of fine particles. 
Table S12. Adjusted association between air pollution exposure during fetal life and cortical thickness (in $\mathrm{mm}$ ) at 6-10 years of age restricting to those children from nonsmoking mothers during pregnancy

\begin{tabular}{|c|c|c|c|c|c|}
\hline & Hemisphere & $\begin{array}{c}\text { Size brain } \\
\text { region }\left(\mathbf{m m}^{2}\right)\end{array}$ & Coef. & $(95 \% \mathrm{CI})^{\mathrm{a}}$ & $P$ value \\
\hline \multicolumn{6}{|l|}{ Fine particles exposure } \\
\hline Precuneus region & Right & 936 & -0.048 & $(-0.065$ to -0.032$)$ & $<.001$ \\
\hline Pars opercularis region & Right & 753 & -0.026 & $(-0.035$ to -0.016$)$ & $<.001$ \\
\hline Pars orbitalis region & Right & 651 & -0.026 & $(-0.041$ to -0.011$)$ & $<.001$ \\
\hline Rostral middle frontal region & Right & 2,995 & -0.028 & $(-0.040$ to -0.017$)$ & $<.001$ \\
\hline Superior frontal region & Right & 722 & -0.027 & $(-0.041$ to -0.013$)$ & $<.001$ \\
\hline Cuneus region & Left & 843 & -0.016 & $(-0.029$ to -0.003$)$ & .016 \\
\hline \multicolumn{6}{|l|}{ Coarse particles exposure } \\
\hline Lateral orbitofrontal region & Right & 565 & -0.042 & $(-0.063$ to -0.022$)$ & $<.001$ \\
\hline \multicolumn{6}{|c|}{ Absorbance of fine particles exposure } \\
\hline Fusiform region & Left & 532 & -0.082 & $(-0.136$ to -0.029$)$ & .003 \\
\hline
\end{tabular}

Abbreviations: CI, confidence interval; Coef, beta coefficient.

${ }^{a}$ Beta coefficient (95\% Confidence Interval) from linear regression model adjusted for parental educational levels, monthly household income, parental countries of birth, parental ages, maternal prenatal smoking, maternal prenatal alcohol use, parental body mass indexes and heights, maternal parity, family status, maternal psychological distress, maternal intelligence quotient, and child sex, age, and genetic ancestry. Coefficients represent the differences in thickness $(\mathrm{mm})$ per each increase of $5 \mu \mathrm{g} / \mathrm{m}^{3}$ of fine particles, $5 \mu \mathrm{g} / \mathrm{m}^{3}$ of coarse particles, and $10^{-5} \mathrm{~m}^{-}$ ${ }^{1}$ of absorbance of fine particles. 


\section{Supplemental References}

1. Pedersen M, Giorgis-Allemand L, Bernard C, Aguilera I, Andersen A-MN, Ballester F, et al. (2013): Ambient air pollution and low birthweight: a European cohort study (ESCAPE). Lancet Respir Med. 1: 695-704.

2. Guxens M, Garcia-Esteban R, Giorgis-Allemand L, Forns J, Badaloni C, Ballester F, et al. (2014): Air pollution during pregnancy and childhood cognitive and psychomotor development: six European birth cohorts. Epidemiol Camb Mass. 25: 636-647.

3. Valeri L, Vanderweele TJ (2013): Mediation analysis allowing for exposure-mediator interactions and causal interpretation: theoretical assumptions and implementation with SAS and SPSS macros. Psychol Methods. 18: 137-150.

4. Cavanna AE, Trimble MR (2006): The precuneus: a review of its functional anatomy and behavioural correlates. Brain J Neurol. 129: 564-583.

5. Chayer C, Freedman M (2001): Frontal lobe functions. Curr Neurol Neurosci Rep. 1: 547552.

6. Weiner KS, Zilles K (2016): The anatomical and functional specialization of the fusiform gyrus. Neuropsychologia. 83: 48-62.

7. Brooks BL, Sherman EMS, Strauss E (2009): NEPSY-II: A Developmental Neuropsychological Assessment, Second Edition. Child Neuropsychol. 16: 80-101.

8. White T, Marroun HE, Nijs I, Schmidt M, Lugt A van der, Wielopolki PA, et al. (2013): Pediatric population-based neuroimaging and the Generation R Study: the intersection of developmental neuroscience and epidemiology. Eur J Epidemiol. 28: 99-111.

9. Mous SE, Schoemaker NK, Blanken LME, Thijssen S, van der Ende J, Polderman TJC, et al. (2016): The association of gender, age, and intelligence with neuropsychological functioning in young typically developing children: The Generation R study. Appl Neuropsychol Child. 1-19. 